\title{
A CLASSIFICAÇÃO INTERNACIONAL DE FUNCIONALIDADE, INCAPACIDADE E SAÚDE: EVOLUÇÃO DAS PUBLICAÇÕES BRASILEIRAS
}

Laura Mol Souza; Francely de Castro e Sousa. A classificação internacional de funcionalidade, incapacidade e saúde: evolução das publicações brasileiras. Revista Saúde Dinâmica, vol. 2, núm.3, 2020. Faculdade Dinâmica do Vale do Piranga. 


\title{
A classificação internacional de funcionalidade, incapacidade e saúde: evolução das publicações brasileiras
}

\author{
International classification of functionality, disability and health: evolution of brazilian \\ publications
}

Laura Mol Souza ${ }^{1}$; Francely de Castro e Sousa ${ }^{2}$

1 Fisioterapeuta, ORCID 0000-0001-8100-7033

${ }^{2}$ Fisioterapeuta, Docente da Faculdade Dinâmica do Vale do Piranga, ORCID 0000-0002-1881-6409

Autor correspondente: laura.mol@hotmail.com.br

\section{Resumo}

A OMS criou em 2001 a Classificação Internacional de Funcionalidade, Incapacidade e Saúde (CIF). A CIF é uma ferramenta usada para classificação do entendimento da funcionalidade e da incapacidade humana, em nível individual e populacional. Objetivou-se quantificar as publicações brasileiras referentes à CIF, de 2003 até 2019, avaliando o seu perfil de utilização, as áreas e as instituições às quais se vinculam as pesquisas. Trata-se de uma revisão integrativa, realizada nas bases de dados Lilacs, SciELO e PubMed. Foram analisadas 53 publicações, a maioria nas áreas de neurologia e que utilizaram a ferramenta para avaliar a funcionalidade. Em relação à distribuição espacial, identificou-se que a maior parte dos estudos foi realizado na região Sudeste e a instituição de ensino que mais publicou a esse respeito em periódicos brasileiros foi a USP. A CIF aparece no cenário mundial como uma ferramenta promissora e com grande potencial de adesão e aplicabilidade, notou-se crescente procura na comunidade científica brasileira, entretanto mais esclarecimentos acerca da ferramenta são necessários para sua inserção na prática.

Palavras-chave: Classificação Internacional de Funcionalidade, Incapacidade e Saúde; CIF; Publicações Brasileiras.

\begin{abstract}
In 2001, WHO created the International Classification of Functioning, Disability and Health (ICF). The ICF is a tool used to classify the understanding of human functionality and disability, at the individual and population level. The objective was to quantify the Brazilian publications referring to the CIF, from 2003 to 2019, evaluating its usage profile, the areas and institutions to which the research is linked. It is an integrative review, carried out in the Lilacs, SciELO and PubMed databases. 53 publications were analyzed, most in the areas of neurology and which used the tool to assess functionality. Regarding the spatial distribution, it was found that most of the studies were carried out in the Southeast region and the educational institution that published the most in this regard in Brazilian journals was USP. The ICF appears on the world stage as a promising tool and with great potential for adherence and applicability, there was a growing demand in the Brazilian scientific community, however more clarification about the tool is necessary for its insertion in practice.
\end{abstract}

Key words: International Classification of Functioning, Disability and Health; ICF; Brazilian Publications. 


\section{INTRODUÇÃO}

De acordo com a Organização Mundial de Saúde (OMS, 2001), a Classificação Internacional de Funcionalidade, Incapacidade e Saúde, mais conhecida como CIF, é uma classificação que envolve diversos domínios relacionados à saúde. A CIF é a ferramenta da OMS usada para classificação e entendimento da funcionalidade e da incapacidade humana, em nível individual e populacional. Foi oficialmente endossada por todos os 191 Estados Membros da OMS na 54 a Assembleia Mundial da Saúde, em 22 de maio de 2001, como o padrão internacional para descrever e medir a saúde e a incapacidade (OMS, 2001).

A CIF tem como objetivo principal padronizar e unificar a linguagem em saúde, seus estados relacionados e seu entendimento, permitindo assim a comunicação entre várias disciplinas e ciências, abrangendo políticas públicas, educação e saúde (BATTISTELLA e BRITO, 2002).

O modelo de funcionalidade e incapacidade apresentado pela OMS adota uma abordagem biopsicossocial que incorpora os componentes de saúde nos níveis corporais e sociais. Assim, na avaliação de uma pessoa com deficiência, esse modelo destaca-se do biomédico, que se baseia no diagnóstico etiológico da disfunção, e evoluiu para um modelo que incorpora as três dimensões: a biomédica, a psicológica (dimensão individual) e a social. Nesse modelo, cada nível age sobre e sofre a ação dos demais, sendo todos influenciados pelos fatores ambientais (FARIAS e BUCHALLA, 2005).

Esse modelo biopsicossocial da OMS admite uma complexa interação e uma completa multidirecionalidade entre seus componentes: transtorno/doença, funções/estruturas, atividades, participação, fatores ambientais e fatores pessoais. Ele contrapõe um modelo linear antecedente, a Classificação Estatística Internacional de Doenças e Problemas Relacionados com a Saúde, frequentemente designada pela sigla CID, em que a desvantagem social era o resultado de problemas que ocorriam em cascata, começando pelo transtorno/doença, passando pela deficiência e depois pela incapacidade. Sabe-se, entretanto, que a análise dos fatores ambientais é muito significativa para conhecimento de determinantes da saúde do indivíduo. Assim, o uso da CIF e do modelo biopsicossocial podem ser caminhos para garantia de uma abordagem ampla em saúde funcional (ARAÚJO, 2013). 
A multidirecionalidade do modelo biopsicossocial permite, por exemplo, que se entenda que a doença seja resultado de alterações da funcionalidade e não a causadora dessas alterações. Permite, ainda, o entendimento da situação diferenciada de incapacidade em que pessoas com a mesma doença, podem ter disfunções diferentes, já que são influenciadas por contextos distintos (ARAÚJO, 2013).

Dentro de cada componente da CIF, existe uma lista extenuante de categorias (representadas por letras e números), que são as unidades da classificação. As categorias da CIF são hierarquicamente organizadas e simbolizadas por caracteres alfanuméricos, com uma letra para nomear o componente ao qual o item se refere: " $b$ " (funções do corpo), "s" (estruturas do corpo), “ $d$ ” (atividades e participação), e “ $e$ ” (fatores ambientais). Na sequência, é adicionado um código numérico com um, três ou quatro dígitos, referente à categoria individual do referido componente. As categorias são dispostas segundo uma organização de tronco-ramo-folha dentro de cada componente (RIBERTO, 2011; DI NUBILA e BUCHALLA, 2008).

Com suas 1.454 categorias, a CIF aborda, de forma completa, a funcionalidade humana, esgotando os componentes descritos anteriormente, o que a torna uma classificação extremamente abrangente e vantajosa, porque aumenta seu poder descritivo. Contudo, este também é um dos maiores desafios ao seu uso prático, pois todas as categorias deveriam ser avaliadas em todas as pessoas, o que é impraticável (RIBERTO, 2011).

A CIF descreve a funcionalidade e a incapacidade relacionadas às condições de saúde, identificando o que uma pessoa "pode ou não pode fazer na sua vida diária", tendo em vista as funções dos órgãos ou sistemas e estruturas do corpo, assim como as limitações de atividades e da participação social no meio ambiente onde a pessoa convive (FARIAS e BUCHALLA, 2005).

De acordo com a Organização Mundial de Saúde, a CIF é uma classificação com múltiplas finalidades, que foi elaborada para servir a várias disciplinas e setores diferentes relacionados à área da saúde. Os seus objetivos específicos podem ser resumidos da seguinte maneira: proporcionar uma base científica para uma melhor descrição, compreensão e estudo da saúde e das condições relacionadas à saúde; estabelecer uma linguagem e modelo padronizado para a descrição da saúde, aperfeiçoando a comunicação entre diferentes usuários, como profissionais de saúde, pesquisadores, elaboradores das políticas públicas e o público em geral; permitir a comparação de dados entre países, entre disciplinas, entre os serviços e 
profissionais da área da saúde; fornecer um esquema de codificação para um sistema de informação completo da área saúde (CIF-CJ, 2011; OMS, 2013).

Como a CIF é uma classificação da saúde e dos estados relacionados com a saúde, também é utilizada por setores, tais como, seguridade, segurança social, trabalho, educação, economia, política social, desenvolvimento de políticas públicas, e de legislação em geral e alterações ambientais. Por esses motivos foi recebida como uma das classificações sociais das Nações Unidas, sendo mencionada e estando incorporada nas Normas Padronizadas para a Igualdade de Oportunidades para Pessoas com Incapacidades. Assim, a CIF constitui um instrumento adequado para o desenvolvimento de legislação internacional sobre os direitos humanos bem como de legislação em nível nacional (CIF-CJ, 2011).

A CIF é útil num âmbito muito amplo de aplicações, e oferece uma estrutura conceitual para a informação aplicável aos cuidados pessoais de saúde, incluindo a prevenção, a promoção da saúde e a melhoria da participação, removendo ou abrandando as barreiras sociais e estimulando a atribuição de apoios e de facilitadores sociais. É também útil no estudo dos sistemas de cuidados de saúde, em termos de avaliação e de formulação de políticas (CIF-CJ, 2011).

Em virtude do crescente interesse da comunidade científica e acadêmica pelo tema, o presente trabalho teve como objetivo quantificar as publicações referentes à Classificação Internacional de Funcionalidade, Incapacidade e Saúde na literatura nacional, desde a sua tradução oficial para língua portuguesa, em 2003, até o ano de 2019, avaliando o seu perfil de utilização, as principais áreas de pesquisa, e as instituições as quais se vinculam as pesquisas.

\section{MATERIAIS E MÉTODOS}

Trata-se de uma revisão integrativa que aborda as publicações nacionais sobre a CIF. A revisão integrativa é um método que proporciona a síntese de conhecimento e a incorporação da aplicabilidade de resultados de estudos significativos na prática (SOUZA; SILVA; CARVALHO, 2010). Além disso, guarda relação com a cienciometria, na medida em que descreve a produtividade científica nacional sobre o tema (PARRA, COUTINHO; PESSANO, 2019). 
Foram consultadas as bases de dados: PubMed (National Library of Medicine, disponível em https://www.ncbi.nlm.nih.gov/pubmed/), Lilacs (Literatura LatinoAmericana e do Caribe em Ciências da Saúde, disponível em https://lilacs.bvsalud.org/) e SciELO (Scientific Electronic Library Online, disponível em https://scielo.org/).

A busca foi concretizada por meio da articulação dos descritores "CIF" e "International Classification of Functioning, Disability and Health" e "Classificação Internacional de Funcionalidade, Incapacidade e Saúde", obtidos na consulta aos Descritores em Ciências da Saúde (DECS). Optou-se por utilizar os termos na língua inglesa e na língua portuguesa e o operador booleano OR. O processo de consulta requereu a presença dos descritores no título e/ou resumo.

Os dados foram coletados durante o mês de agosto de 2019, e para pesquisa foi considerado o período de 2003 (ano de tradução oficial da CIF para língua portuguesa pela OMS) até julho de 2019, para garantir atualidade do tema, uma vez que a pesquisa foi realizada em agosto de 2019.

Os critérios de inclusão adotados foram: trabalhos publicados na forma de artigo científico; textos completos disponíveis de forma gratuita; publicações em português; trabalhos que tenham sido desenvolvidos no Brasil ou com a participação de instituições brasileiras, já que esse estudo abordou a produção nacional; publicações que se refiram à utilização da CIF como ferramenta principal de avaliação ou que explorem seus conceitos e propriedades.

Ao se aplicar a metodologia proposta nas bases de dados, foram encontrados 93 artigos relacionados à temática da pesquisa, conforme ilustra o Quadro 1. 
Quadro 1. Estratégia de busca e quantitativo de artigos encontrados nas bases de dados e no diretório de pesquisa.

\begin{tabular}{|c|c|c|}
\hline $\begin{array}{c}\text { Base De } \\
\text { dados }\end{array}$ & Estratégia de busca & $\begin{array}{c}\text { Artigos } \\
\text { encontrados }\end{array}$ \\
\hline Lilacs & $\begin{array}{r}\text { "CIF" OR "International Classification of Functioning, } \\
\text { Disability and Health" OR "Classificação Internacional } \\
\text { de Funcionalidade, Incapacidade e Saúde" }\end{array}$ & 49 \\
\hline SciELO & $\begin{array}{r}\text { "CIF" OR "International Classification of Functioning, } \\
\text { Disability and Health" OR "Classificação Internacional } \\
\text { de Funcionalidade, Incapacidade e Saúde" }\end{array}$ & 30 \\
\hline PubMed & $\begin{array}{r}\text { "CIF" OR "International Classification of Functioning, } \\
\text { Disability and Health" OR "Classificação Internacional } \\
\text { de Funcionalidade, Incapacidade e Saúde" }\end{array}$ & 14 \\
\hline
\end{tabular}

Fonte: Pesquisa bibliográfica dos autores.

Os artigos encontrados foram analisados primeiramente pelo título e resumo. $\mathrm{Na}$ sequência, foi realizada uma leitura exploratória dos artigos na íntegra. Posteriormente foram selecionados, os artigos que atenderam aos critérios de inclusão e descartados aqueles que não correspondiam à pesquisa.

Após a leitura dos títulos e resumos, 11 artigos foram excluídos por apresentarem duplicidade, e 21 por não se adequarem à proposta, restando 61 artigos para leitura. Por meio da leitura integral, foram selecionados, a partir dos critérios de inclusão e exclusão, 53 artigos para compor a amostra, conforme ilustra o Fluxograma 1. 
Fluxograma 1. Processo de seleção dos artigos para a construção da revisão.
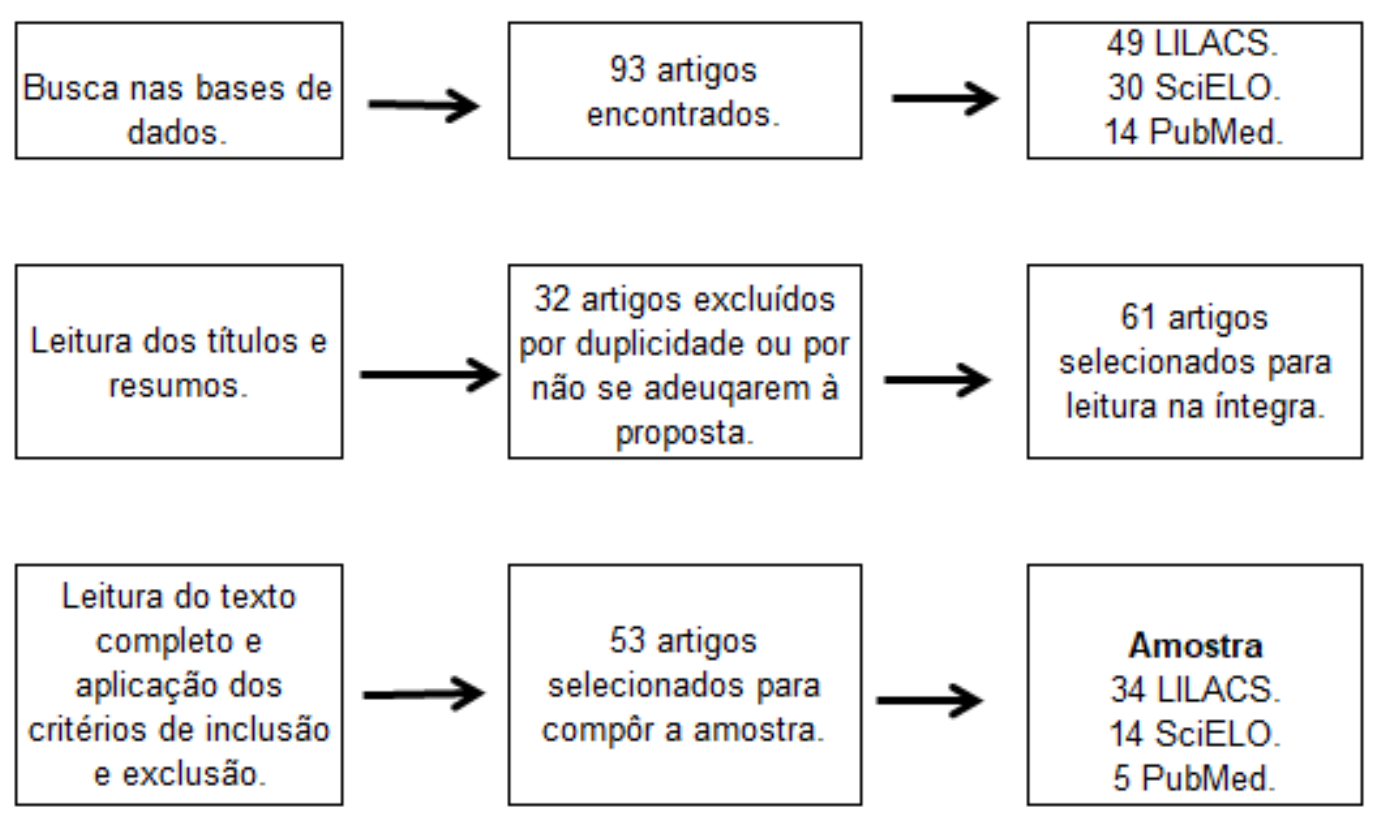

Fonte: Pesquisa bibliográfica dos autores.

\section{RESULTADOS E DISCUSSÃO}

O Gráfico 1 apresenta o quantitativo de produções brasileiras agrupadas por ano de publicação. Observou-se que o número de publicações vem crescendo, devido ao aumento do interesse da comunidade científica e acadêmica na CIF. Ressalta-se que, no limite final do marco cronológico da pesquisa, o ano de 2019, foram contabilizados, apenas, os estudos do primeiro semestre. 
Gráfico 1: Evolução das publicações referentes à CIF no período entre 2005-2019

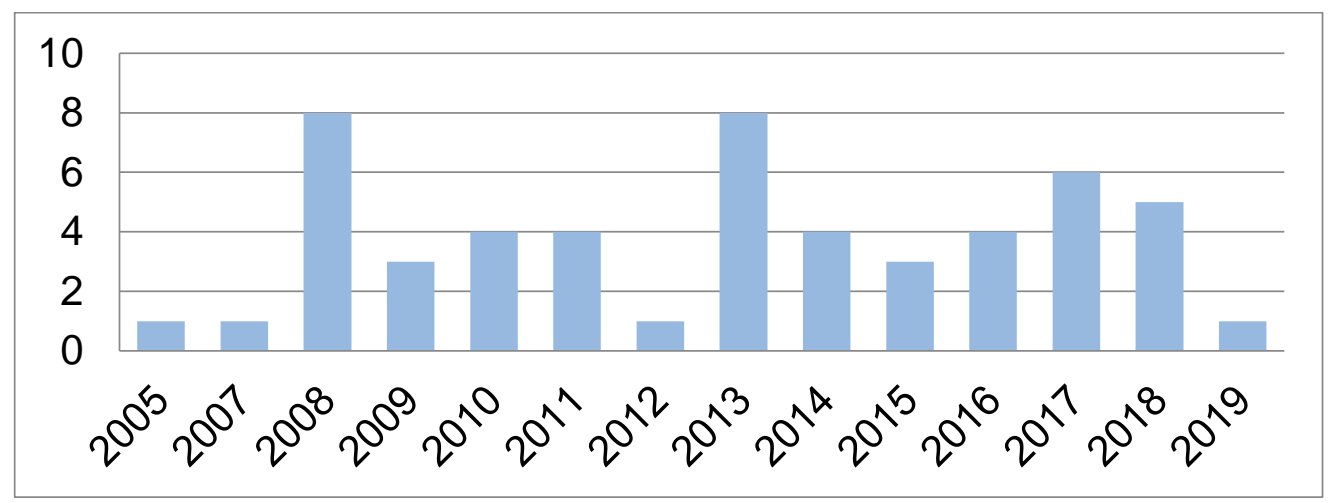

Fonte: Pesquisa bibliográfica dos autores.

A CIF aparece no cenário mundial como uma ferramenta promissora e com grande potencial de adesão e aplicabilidade. Embora esteja ocorrendo um aumento no número das publicações relacionadas à classificação no Brasil, ainda são poucas se comparadas a outros países, especialmente os da Europa (CASTANEDA e CASTRO, 2013).

Para melhor discussão dos artigos encontrados, foi organizado o Quadro 2, em ordem crescente de ano de publicação, evidenciando autores, título e demais informações a discutir.

Quadro 2. Distribuição dos artigos publicados de acordo com ano de publicação, autores, título, área/tema predominante, instituição/instituições e utilização da CIF.

\begin{tabular}{|c|c|c|c|c|}
\hline Autor(es)/Ano & Título & Área/Tema & Instituição - UF & Utilização da CIF \\
\hline $\begin{array}{c}\text { FARIAS e } \\
\text { BUCHALLA, } \\
2005\end{array}$ & $\begin{array}{c}\text { A Classificação } \\
\text { Internacional de } \\
\text { Funcionalidade, } \\
\text { Incapacidade e Saúde da } \\
\text { Organização Mundial da } \\
\text { Saúde: Conceitos, Usos e } \\
\text { Perspectivas. }\end{array}$ & Conceitual & USP - SP & Explicação da CIF. \\
\hline $\begin{array}{l}\text { DINIZ, } \\
\text { MEDEIROS e } \\
\text { SQUINCA, } \\
2007\end{array}$ & $\begin{array}{l}\text { Reflexões sobre a versão em } \\
\text { Português da Classificação } \\
\text { Internacional de } \\
\text { Funcionalidade, } \\
\text { Incapacidade e Saúde. }\end{array}$ & Conceitual & UNB - DF & $\begin{array}{l}\text { Sugestão de nova } \\
\text { tradução. }\end{array}$ \\
\hline & 6 \\
\hline & $\begin{array}{c}\text { CA - Revista Cientifica Eletrönic } \\
\text { | Ano II, no } 3 \text { | ISSN-2675-1 }\end{array}$ & & & \\
\hline
\end{tabular}




\begin{tabular}{|c|c|c|c|c|}
\hline Autor(es)/Ano & Título & Área/Tema & Instituição - UF & Utilização da CIF \\
\hline $\begin{array}{c}\text { RIBERTO, } \\
\text { SARON e } \\
\text { BATTISTELLA, } \\
2008\end{array}$ & $\begin{array}{l}\text { Resultados do core set da } \\
\text { CIF de dor crônica } \\
\text { generalizada em mulheres } \\
\text { com fibromialgia no Brasil. }\end{array}$ & Ortopedia & USP - SP & $\begin{array}{c}\text { Avaliação da } \\
\text { possibilidade de } \\
\text { utilização do Core } \\
\text { Set da CIF de dor } \\
\text { crônica generalizada, } \\
\text { em mulheres com } \\
\text { fibromialgia. }\end{array}$ \\
\hline $\begin{array}{c}\text { BUCHALLA e } \\
\text { CAVALHEIRO, } \\
2008\end{array}$ & $\begin{array}{c}\text { A Classificação } \\
\text { Internacional de } \\
\text { Funcionalidade, } \\
\text { Incapacidade e Saúde e a } \\
\text { Aids: uma proposta de core } \\
\text { set. }\end{array}$ & Infectologia & USP - SP & $\begin{array}{l}\text { Desenvolvimento de } \\
\text { um Core Set para } \\
\text { pacientes portadores } \\
\text { do vírus da AIDS. }\end{array}$ \\
\hline $\begin{array}{c}\text { CASTRO et al., } \\
2008\end{array}$ & $\begin{array}{l}\text { Qualidade de vida em } \\
\text { diabetes mellitus e } \\
\text { Classificação Internacional } \\
\text { de Funcionalidade, } \\
\text { Incapacidade e Saúde - } \\
\text { estudo de alguns aspectos }\end{array}$ & $\begin{array}{l}\text { Endocrinolo } \\
\text { gia }\end{array}$ & UFRJ - RJ & $\begin{array}{l}\text { Utilização do Core } \\
\text { Set resumido para } \\
\text { Diabetes Mellitus, a } \\
\text { fim de avaliar a } \\
\text { qualidade de vida de } \\
\text { pacientes com DM. }\end{array}$ \\
\hline $\begin{array}{l}\text { SILVA, NEVES } \\
\text { e RIBERTO, } \\
2008\end{array}$ & $\begin{array}{l}\text { A formação fisioterapêutica } \\
\text { no campo da ortopedia: uma } \\
\text { visão crítica sob a óptica da } \\
\text { funcionalidade }\end{array}$ & Ortopedia & UFBA - BA & $\begin{array}{l}\text { Rastreamento dos } \\
\text { componentes da CIF } \\
\text { registrados nos } \\
\text { prontuários por } \\
\text { acadêmicos de } \\
\text { fisioterapia. }\end{array}$ \\
\hline $\begin{array}{l}\text { SABINO, } \\
\text { COELHO e } \\
\text { SAMPAIO, } \\
2008\end{array}$ & $\begin{array}{l}\text { Utilização da Classificação } \\
\text { Internacional de } \\
\text { Funcionalidade, } \\
\text { Incapacidade e Saúde na } \\
\text { avaliação fisioterapêutica de } \\
\text { indivíduos com problemas } \\
\text { musculoesqueléticos nos } \\
\text { membros inferiores e região } \\
\text { lombar }\end{array}$ & Ortopedia & UFMG - MG & $\begin{array}{c}\text { Análise das } \\
\text { dificuldades de } \\
\text { utilização da CIF } \\
\text { para codificar } \\
\text { atividades e } \\
\text { participação em } \\
\text { pacientes com } \\
\text { problemas } \\
\text { musculoesqueléticos } \\
\text { em MMII e coluna } \\
\text { lombar. }\end{array}$ \\
\hline
\end{tabular}




\begin{tabular}{|c|c|c|c|c|}
\hline Autor(es)/Ano & Título & Área/Tema & Instituição - UF & Utilização da CIF \\
\hline $\begin{array}{l}\text { BRASILEIRO e } \\
\text { MOREIRA, } \\
2008\end{array}$ & $\begin{array}{l}\text { Prevalência de alterações } \\
\text { funcionais corpóreas em } \\
\text { crianças com paralisia } \\
\text { cerebral, Fortaleza, Ceará, } \\
2006\end{array}$ & $\begin{array}{c}\text { Neurologia e } \\
\text { Pediatria }\end{array}$ & $\begin{array}{l}\text { UFC - CE } \\
\text { UECE - CE }\end{array}$ & $\begin{array}{l}\text { Utilização da CIF } \\
\text { para descrever a } \\
\text { prevalência de } \\
\text { alterações funcionais } \\
\text { corpóreas de um } \\
\text { grupo de crianças } \\
\text { com paralisia } \\
\text { cerebral. }\end{array}$ \\
\hline $\begin{array}{l}\text { DI NUBILA e } \\
\text { BUCHALLA, } \\
\quad 2008\end{array}$ & $\begin{array}{l}\text { O papel das Classificações } \\
\text { da OMS - CID e CIF nas } \\
\text { definições de deficiência e } \\
\text { incapacidade }\end{array}$ & Conceitual & USP - SP & $\begin{array}{c}\text { Descrição dos } \\
\text { elementos da CIF, e } \\
\text { o papel que } \\
\text { desempenham para } \\
\text { definir deficiência e } \\
\text { incapacidade. }\end{array}$ \\
\hline $\begin{array}{l}\text { LIMA et al., } \\
\qquad 2008\end{array}$ & $\begin{array}{l}\text { Avaliação da funcionalidade } \\
\text { dos trabalhadores com } \\
\text { LER/DORT: a construção do } \\
\text { Core Set da CIF para } \\
\text { LER/DORT }\end{array}$ & Ortopedia & UFBA - BA & $\begin{array}{c}\text { Processo de } \\
\text { construção do Core } \\
\text { Set da CIF para } \\
\text { LER/DORT }\end{array}$ \\
\hline $\begin{array}{l}\text { DEPOLITO, } \\
\text { LEOCADIO e } \\
\text { CORDEIRO, } \\
2009\end{array}$ & $\begin{array}{l}\text { Declínio funcional de idosa } \\
\text { institucionalizada: } \\
\text { aplicabilidade do modelo da } \\
\text { Classificação Internacional } \\
\text { de Funcionalidade, } \\
\text { Incapacidade e Saúde }\end{array}$ & Geriatria & UNIFESP - SP & $\begin{array}{l}\text { CIF no relato da } \\
\text { evolução clínica } \\
\text { funcional de uma } \\
\text { idosa. }\end{array}$ \\
\hline $\begin{array}{l}\text { BRASILEIRO, } \\
\text { MOREIRA e } \\
\text { JORGE, } 2009\end{array}$ & $\begin{array}{l}\text { Interveniência dos fatores } \\
\text { ambientais na vida de } \\
\text { crianças com paralisia } \\
\text { cerebral }\end{array}$ & $\begin{array}{c}\text { Neurologia e } \\
\text { Pediatria }\end{array}$ & $\begin{array}{c}\text { UFC - CE } \\
\text { UECE - CE }\end{array}$ & $\begin{array}{c}\text { Influência dos } \\
\text { fatores ambientais } \\
\text { nas atividades e } \\
\text { participação } \\
\text { cotidianas de } \\
\text { crianças com } \\
\text { paralisia cerebral. }\end{array}$ \\
\hline $\begin{array}{c}\text { MAENO, } \\
\text { TAKAHASHI e } \\
\text { LIMA, } 2009\end{array}$ & $\begin{array}{l}\text { Reabilitação profissional } \\
\text { como política de inclusão } \\
\text { social }\end{array}$ & $\begin{array}{l}\text { Medicina do } \\
\text { Trabalho }\end{array}$ & Fundacentro - SP & $\begin{array}{l}\text { O uso da CIF como } \\
\text { ferramenta na }\end{array}$ \\
\hline
\end{tabular}




\begin{tabular}{|c|c|c|c|c|}
\hline Autor(es)/Ano & Título & Área/Tema & Instituição - UF & Utilização da CIF \\
\hline & & & & $\begin{array}{l}\text { reabilitação } \\
\text { profissional. }\end{array}$ \\
\hline $\begin{array}{l}\text { NICKEL } \text { et al., } \\
2010\end{array}$ & $\begin{array}{l}\text { Estudo descritivo do } \\
\text { desempenho ocupacional do } \\
\text { sujeito com doença de } \\
\text { Parkinson: o uso da CIF } \\
\text { como ferramenta para } \\
\text { classificação da atividade e } \\
\text { participação }\end{array}$ & Neurologia & UFPR - PR & $\begin{array}{l}\text { Classificação da } \\
\text { Medida de } \\
\text { Desempenho } \\
\text { Ocupacional } \\
\text { Canadense nos } \\
\text { domínios da CIF em } \\
\text { pacientes com } \\
\text { Parkinson. }\end{array}$ \\
\hline $\begin{array}{l}\text { CASTANEDA e } \\
\text { PLÁCIDO, } 2010\end{array}$ & $\begin{array}{l}\text { Ligação do King's Heath } \\
\text { Questionário com a } \\
\text { Classificação Internacional } \\
\text { de Funcionalidade, } \\
\text { Incapacidade e Saúde, para } \\
\text { avaliação de pacientes com } \\
\text { incontinência urinária pós- } \\
\text { cirurgia oncológica } \\
\text { ginecológica }\end{array}$ & $\begin{array}{l}\text { Saúde da } \\
\text { Mulher }\end{array}$ & $\begin{array}{l}\text { INICID - RJ } \\
\text { IN Câncer - RJ }\end{array}$ & $\begin{array}{c}\text { Relação entre o } \\
\text { King's Health } \\
\text { questionário e a CIF. }\end{array}$ \\
\hline $\begin{array}{l}\text { SIMONELLI et } \\
\text { al., } 2010\end{array}$ & $\begin{array}{l}\text { Proposta de articulação entre } \\
\text { abordagens metodológicas } \\
\text { para melhoria do processo de } \\
\text { reabilitação profissional }\end{array}$ & $\begin{array}{c}\text { Metodologia } \\
\text { e Medicina } \\
\text { do Trabalho }\end{array}$ & UFSCAR - SP & $\begin{array}{l}\text { Utilização da CIF } \\
\text { como modelo de } \\
\text { reinserção do } \\
\text { programa de } \\
\text { reabilitação } \\
\text { profissional do } \\
\text { INSS. }\end{array}$ \\
\hline $\begin{array}{l}\text { FARIA et al., } \\
2010\end{array}$ & $\begin{array}{c}\text { Comparação entre } \\
\text { indivíduos hemiparéticos } \\
\text { com e sem histórico de } \\
\text { quedas com base nos } \\
\text { componentes da } \\
\text { Classificação Internacional } \\
\text { de Funcionalidade, } \\
\text { Incapacidade e Saúde }\end{array}$ & Neurologia & UFMG - MG & $\begin{array}{c}\text { Comparação de } \\
\text { hemiparéticos com e } \\
\text { sem história de } \\
\text { quedas, } \\
\text { considerando os } \\
\text { diferentes } \\
\text { componentes da CIF. }\end{array}$ \\
\hline
\end{tabular}




\begin{tabular}{|c|c|c|c|c|}
\hline Autor(es)/Ano & Título & Área/Tema & Instituição - UF & Utilização da CIF \\
\hline $\begin{array}{c}\text { RIBERTO } \text { et al. }, \\
2011\end{array}$ & $\begin{array}{c}\text { A experiência brasileira com } \\
\text { o Core Set da Classificação } \\
\text { Internacional de } \\
\text { Funcionalidade, } \\
\text { Incapacidade e Saúde para } \\
\text { lombalgia }\end{array}$ & Ortopedia & FMUSP - SP & $\begin{array}{c}\text { Verificação empírica } \\
\text { da validade do core } \\
\text { set da CIF para } \\
\text { lombalgia. }\end{array}$ \\
\hline RIBERTO, 2011 & $\begin{array}{c}\text { Core sets da Classificação } \\
\text { Internacional de } \\
\text { Funcionalidade, } \\
\text { Incapacidade e Saúde }\end{array}$ & Conceitual & USP - SP & $\begin{array}{l}\text { Descrição dos Core } \\
\text { Sets da CIF. }\end{array}$ \\
\hline $\begin{array}{c}\text { NICKEL } \text { et al., } \\
2011\end{array}$ & $\begin{array}{l}\text { Estudo descritivo sobre o } \\
\text { desempenho ocupacional do } \\
\text { sujeito com epilepsia: o uso } \\
\text { da CIF como ferramenta } \\
\text { para classificação da } \\
\text { atividade e participação }\end{array}$ & Neurologia & UFPR - PR & $\begin{array}{c}\text { Análise das } \\
\text { principais limitações } \\
\text { no desempenho em } \\
\text { atividades e } \\
\text { restrições na } \\
\text { participação do } \\
\text { sujeito com } \\
\text { epilepsia, } \\
\text { classificadas de } \\
\text { acordo com a CIF. }\end{array}$ \\
\hline $\begin{array}{l}\text { LUCENA et al., } \\
2011\end{array}$ & $\begin{array}{l}\text { A funcionalidade de usuários } \\
\text { acometidos por AVE em } \\
\text { conformidade com a } \\
\text { acessibilidade à reabilitação }\end{array}$ & Neurologia & UFPR - PR & $\begin{array}{c}\text { Classificação dos } \\
\text { componentes da CIF } \\
\text { na atividade e } \\
\text { participação em } \\
\text { indivíduos com } \\
\text { AVE. }\end{array}$ \\
\hline $\begin{array}{l}\text { CARDOSO, } \\
\text { MAGALHAES } \\
\text { e LACERDA, } \\
2012\end{array}$ & $\begin{array}{l}\text { Relação entre a Avaliação da } \\
\text { Coordenação e Destreza } \\
\text { Motora (Acoordem) e a } \\
\text { Classificação Internacional } \\
\text { de Funcionalidade, } \\
\text { Incapacidade e Saúde (CIF) }\end{array}$ & Ortopedia & UFMG - MG & $\begin{array}{l}\text { Utilização da CIF-CJ } \\
\text { numa comparação } \\
\text { com itens contidos } \\
\text { na Acoordem. }\end{array}$ \\
\hline $\begin{array}{c}\text { MONTEIRO et } \\
\text { al., } 2013\end{array}$ & $\begin{array}{l}\text { Caracterização Funcional de } \\
\text { Indivíduos Acometidos por } \\
\text { Acidente Vascular } \\
\text { Encefálico Assistidos em }\end{array}$ & Neurologia & UEPB - PB & $\begin{array}{c}\text { Utilização da CIF } \\
\text { como avaliação }\end{array}$ \\
\hline
\end{tabular}




\begin{tabular}{|c|c|c|c|c|}
\hline Autor(es)/Ano & Título & Área/Tema & Instituição - UF & Utilização da CIF \\
\hline & $\begin{array}{l}\text { uma Unidade de Terapia } \\
\text { Intensiva }\end{array}$ & & & $\begin{array}{l}\text { sociodemográfica de } \\
\text { pacientes com AVE. }\end{array}$ \\
\hline $\begin{array}{l}\text { MORETTIN et } \\
a l ., 2013\end{array}$ & $\begin{array}{l}\text { O uso da Classificação } \\
\text { Internacional de } \\
\text { Funcionalidade, } \\
\text { Incapacidade e Saúde para } \\
\text { acompanhamento de } \\
\text { pacientes usuários de } \\
\text { Implante Coclear }\end{array}$ & $\begin{array}{l}\text { Pediatria e } \\
\text { Deficiência } \\
\text { Auditiva }\end{array}$ & USP - SP & $\begin{array}{l}\text { Utilização da CIF-CJ } \\
\text { para caracterizar o } \\
\text { perfil dos pacientes } \\
\text { usuários com } \\
\text { Implante Coclear. }\end{array}$ \\
\hline $\begin{array}{c}\text { ARAUJO e } \\
\text { BUCHALLA, } \\
2013\end{array}$ & $\begin{array}{l}\text { Utilização da CIF em } \\
\text { fisioterapia do trabalho: uma } \\
\text { contribuição para coleta de } \\
\text { dados sobre funcionalidade }\end{array}$ & $\begin{array}{c}\text { Medicina do } \\
\text { Trabalho }\end{array}$ & USP - SP & $\begin{array}{l}\text { Utilização da CIF } \\
\text { como instrumento } \\
\text { para a coleta de } \\
\text { dados sobre } \\
\text { funcionalidade, para } \\
\text { uso na especialidade } \\
\text { de Fisioterapia do } \\
\text { Trabalho. }\end{array}$ \\
\hline $\begin{array}{l}\text { CASTANEDA e } \\
\text { CASTRO, } 2013\end{array}$ & $\begin{array}{l}\text { Publicações brasileiras } \\
\text { referentes à Classificação } \\
\text { Internacional de } \\
\text { Funcionalidade }\end{array}$ & $\begin{array}{l}\text { Conceitual e } \\
\text { Metodologia }\end{array}$ & UFTM - MG & $\begin{array}{c}\text { Descrição e } \\
\text { classificação das } \\
\text { publicações sobre } \\
\text { CIF. }\end{array}$ \\
\hline $\begin{array}{l}\text { FERREIRA, } \\
\text { FOLHA e } \\
\text { TOBIAS, } 2013\end{array}$ & $\begin{array}{l}\text { Avaliação da percepção } \\
\text { sobre o ambiente de } \\
\text { circulação: a acessibilidade } \\
\text { centrada no usuário }\end{array}$ & $\begin{array}{c}\text { Meio } \\
\text { Ambiente }\end{array}$ & $\begin{array}{l}\text { UNAMA -PA } \\
\text { USP - SP } \\
\text { UFPA - PA }\end{array}$ & $\begin{array}{l}\text { Utilização dos } \\
\text { componentes da CIF } \\
\text { para avaliar um } \\
\text { espaço público de } \\
\text { circulação }\end{array}$ \\
\hline $\begin{array}{l}\text { SANTOS et al., } \\
2013\end{array}$ & $\begin{array}{l}\text { Classificação Internacional } \\
\text { de Funcionalidade, } \\
\text { Incapacidade e Saúde: } \\
\text { utilização no cuidado de } \\
\text { enfermagem a pessoas } \\
\text { idosas }\end{array}$ & Geriatria & FURG - RS & $\begin{array}{l}\text { Utilização da CIF } \\
\text { para refletir o } \\
\text { cuidado de } \\
\text { enfermagem com a } \\
\text { pessoa idosa. }\end{array}$ \\
\hline $\begin{array}{l}\text { SILVA et al., } \\
2013\end{array}$ & $\begin{array}{c}\text { Comparação entre } \\
\text { instrumentos de qualidade de } \\
\text { vida para avaliação da }\end{array}$ & Neurologia & UNINOVE - SP & $\begin{array}{l}\text { Avaliação de dois } \\
\text { questionários de } \\
\text { qualidade de vida }\end{array}$ \\
\hline
\end{tabular}




\begin{tabular}{|c|c|c|c|c|}
\hline$\overline{\text { Autor(es)/Ano }}$ & $\overline{\text { Título }}$ & Área/Tema & Instituição - UF & Utilização da CIF \\
\hline & $\begin{array}{l}\text { participação após AVE } \\
\text { conforme a Classificação } \\
\text { Internacional de } \\
\text { Funcionalidade, } \\
\text { Incapacidade e Saúde (CIF) }\end{array}$ & & & $\begin{array}{l}\text { comparando-os com } \\
\text { componente de } \\
\text { participação da CIF } \\
\text { em indivíduos com } \\
\text { AVE. }\end{array}$ \\
\hline $\begin{array}{c}\text { STOFFEL e } \\
\text { NICKEL, } 2013\end{array}$ & $\begin{array}{l}\text { A utilização da atividade } \\
\text { como ferramenta no } \\
\text { processo de intervenção do } \\
\text { terapeuta ocupacional em } \\
\text { reabilitação neurológica }\end{array}$ & Neurologia & UFPR - PR & $\begin{array}{l}\text { Comparação dos } \\
\text { termos da CIF com } \\
\text { outros dois } \\
\text { instrumentos de } \\
\text { avaliação para } \\
\text { reabilitação } \\
\text { neurológica. }\end{array}$ \\
\hline $\begin{array}{c}\text { CASTRO, } \\
\text { CANEDA e } \\
\text { SILVEIRA, } \\
2014\end{array}$ & $\begin{array}{l}\text { Identificação de conteúdo } \\
\text { comum entre o questionário } \\
\text { do Inquérito de Saúde (ISA- } \\
\text { SP) e a Classificação } \\
\text { Internacional de } \\
\text { Funcionalidade, } \\
\text { Incapacidade e Saúde }\end{array}$ & Metodologia & UFTM - MG & $\begin{array}{c}\text { Identificação dos } \\
\text { conteúdos comuns } \\
\text { entre o Questionário } \\
\text { do Inquérito de } \\
\text { Saúde de São Paulo } \\
\text { e a CIF. }\end{array}$ \\
\hline $\begin{array}{l}\text { CASTANEDA, } \\
\text { BERGMANN e } \\
\text { BAHIA, } 2014\end{array}$ & $\begin{array}{c}\text { A Classificação } \\
\text { Internacional de } \\
\text { Funcionalidade, } \\
\text { Incapacidade e Saúde: uma } \\
\text { revisão sistemática de } \\
\text { estudos observacionais }\end{array}$ & $\begin{array}{l}\text { Conceitual e } \\
\text { Metodologia }\end{array}$ & UFRJ - RJ & $\begin{array}{c}\text { Revisão sobre a CIF } \\
\text { em estudos } \\
\text { observacionais. }\end{array}$ \\
\hline $\begin{array}{l}\text { CASTANEDA, } \\
\text { CASTRO e } \\
\text { BAHIA, } 2014\end{array}$ & $\begin{array}{l}\text { Construtos de incapacidade } \\
\text { presentes na Pesquisa } \\
\text { Nacional por Amostra de } \\
\text { Domicílio (PNAD): uma } \\
\text { análise baseada na } \\
\text { Classificação Internacional } \\
\text { de Funcionalidade, } \\
\text { Incapacidade e Saúde (CIF) }\end{array}$ & Metodologia & UFRJ - RJ & $\begin{array}{l}\text { Comparação dos } \\
\text { construtos de } \\
\text { incapacidade } \\
\text { presentes na } \\
\text { Pesquisa Nacional } \\
\text { por Amostra de } \\
\text { Domicílio (PNAD) } \\
\text { com a CIF. }\end{array}$ \\
\hline $\begin{array}{c}\text { LOPES e } \\
\text { SANTOS, } 2015\end{array}$ & $\begin{array}{l}\text { Funcionalidade de idosos } \\
\text { cadastrados em uma unidade } \\
\text { da Estratégia Saúde da }\end{array}$ & Geriatria & UEPA - PA & $\begin{array}{l}\text { Investigação da } \\
\text { funcionalidade de }\end{array}$ \\
\hline
\end{tabular}




\begin{tabular}{|c|c|c|c|c|}
\hline$\overline{\text { Autor(es)/Ano }}$ & $\overline{\text { Título }}$ & Área/Tema & Instituição - UF & Utilização da CIF \\
\hline & $\begin{array}{l}\text { Família segundo categorias } \\
\text { da Classificação } \\
\text { Internacional de } \\
\text { Funcionalidade }\end{array}$ & & & $\begin{array}{l}\text { idosos, utilizando } \\
\text { categorias da CIF. }\end{array}$ \\
\hline $\begin{array}{l}\text { ARAUJO e } \\
\text { BUCHALLA, } \\
2015\end{array}$ & $\begin{array}{c}\text { O uso da Classificação } \\
\text { Internacional de } \\
\text { Funcionalidade, } \\
\text { Incapacidade e Saúde } \\
\text { em inquéritos de saúde: uma } \\
\text { reflexão } \\
\text { sobre limites e } \\
\text { possibilidades }\end{array}$ & $\begin{array}{l}\text { Conceitual e } \\
\text { Metodologia }\end{array}$ & USP - SP & $\begin{array}{c}\text { Reflexão sobre o uso } \\
\text { da CIF. }\end{array}$ \\
\hline $\begin{array}{l}\text { ZAPONI et al., } \\
2015\end{array}$ & $\begin{array}{l}\text { Avaliação da qualidade de } \\
\text { vida de portadores de } \\
\text { insuficiência cardíaca } \\
\text { congestiva e sua correlação } \\
\text { com a Classificação } \\
\text { Internacional de } \\
\text { Funcionalidade, } \\
\text { Incapacidade e Saúde }\end{array}$ & Cardiologia & $\begin{array}{c}\text { UNICENTRO - } \\
\text { PR }\end{array}$ & $\begin{array}{c}\text { Relação entre o } \\
\text { questionário de } \\
\text { qualidade de vida e a } \\
\text { CIF em pacientes } \\
\text { com Insuficiência } \\
\text { Cardíaca Congestiva. }\end{array}$ \\
\hline $\begin{array}{l}\text { ARAUJO et al. } \\
2015\end{array}$ & $\begin{array}{l}\text { Investigação dos saberes } \\
\text { quanto à capacidade } \\
\text { funcional e qualidade de } \\
\text { vida em idosas } \\
\text { institucionalizadas, sob a } \\
\text { ótica da CIF }\end{array}$ & Geriatria & UFPR - PR & $\begin{array}{l}\text { Utilização da CIF } \\
\text { para avaliar a } \\
\text { funcionalidade de } \\
\text { idosas. }\end{array}$ \\
\hline $\begin{array}{l}\text { SILVA et al., } \\
\quad 2016\end{array}$ & $\begin{array}{l}\text { Aplicação da classificação } \\
\text { internacional de } \\
\text { funcionalidade, incapacidade } \\
\text { e saúde em Unidade de } \\
\text { Terapia Intensiva } \\
\text { Cardiotorácica }\end{array}$ & $\begin{array}{c}\text { Terapia } \\
\text { Intensiva e } \\
\text { Cardiologia }\end{array}$ & UFS - SE & $\begin{array}{l}\text { Utilização da CIF } \\
\text { para codificar a } \\
\text { funcionalidade dos } \\
\text { pacientes com } \\
\text { disfunções do } \\
\text { sistema } \\
\text { cardiovascular } \\
\text { internados em uma } \\
\text { UTI. }\end{array}$ \\
\hline
\end{tabular}




\begin{tabular}{|c|c|c|c|c|}
\hline Autor(es)/Ano & Título & Área/Tema & Instituição - UF & Utilização da CIF \\
\hline $\begin{array}{l}\text { OVANDO et al., } \\
2016\end{array}$ & $\begin{array}{l}\text { Processo de tradução, } \\
\text { propriedades de medida e } \\
\text { classificação de acordo a } \\
\text { CIF dos instrumentos de } \\
\text { avaliação pós-AVE } \\
\text { disponíveis em Português } \\
\text { falado no Brasil }\end{array}$ & Neurologia & UDESC - SC & $\begin{array}{c}\text { Avaliação da } \\
\text { qualidade } \\
\text { metodológica dos } \\
\text { processos de } \\
\text { tradução e adaptação } \\
\text { de instrumentos de } \\
\text { avaliação em } \\
\text { Neurologia com base } \\
\text { na CIF. }\end{array}$ \\
\hline $\begin{array}{l}\text { POMMEREHN, } \\
\text { DELBONI e } \\
\text { FEDOSSE, } 2016\end{array}$ & $\begin{array}{l}\text { Classificação Internacional } \\
\text { de Funcionalidade, } \\
\text { Incapacidade e Saúde e } \\
\text { afasia: um estudo da } \\
\text { participação social }\end{array}$ & $\begin{array}{l}\text { Neurologia e } \\
\text { Fonoaudiolo } \\
\text { gia }\end{array}$ & UFSM - RS & $\begin{array}{l}\text { Análise do impacto } \\
\text { das afasias na } \\
\text { participação social e } \\
\text { nas atividades dos } \\
\text { indivíduos por elas } \\
\text { acometidas, } \\
\text { utilizando critérios } \\
\text { da CIF. }\end{array}$ \\
\hline $\begin{array}{c}\text { CASTRO et al., } \\
2016\end{array}$ & $\begin{array}{l}\text { Aferição de funcionalidade } \\
\text { em inquéritos de saúde no } \\
\text { Brasil: discussão sobre } \\
\text { instrumentos baseados na } \\
\text { Classificação Internacional } \\
\text { de Funcionalidade, } \\
\text { Incapacidade e Saúde (CIF) }\end{array}$ & Metodologia & UFC - CE & $\begin{array}{l}\text { Investigação da } \\
\text { possibilidade da } \\
\text { aplicação da CIF em } \\
\text { inquéritos de saúde. }\end{array}$ \\
\hline $\begin{array}{l}\text { OLIVEIRA et } \\
\text { al., } 2017\end{array}$ & $\begin{array}{l}\text { Proposta de utilização da } \\
\text { Classificação Internacional } \\
\text { de Funcionalidade, } \\
\text { Incapacidade e Saúde na } \\
\text { avaliação da disfunção } \\
\text { temporomandibular }\end{array}$ & Ortopedia & UFC - CE & $\begin{array}{c}\text { Avaliação do } \\
\text { Research Diagnostic } \\
\text { Criteria for } \\
\text { Temporomandibular } \\
\text { Disorders e } \\
\text { comparação com } \\
\text { componentes da CIF. }\end{array}$ \\
\hline $\begin{array}{l}\text { FLEIG et al., } \\
2017\end{array}$ & $\begin{array}{l}\text { Alterações cognitivas em } \\
\text { portadores de doenças } \\
\text { crônicas e sua relação com a } \\
\text { classificação internacional }\end{array}$ & Geriatria & UNISC - RS & $\begin{array}{c}\text { Utilização da CIF } \\
\text { para analisar } \\
\text { alterações cognitivas } \\
\text { de idosos portadores }\end{array}$ \\
\hline
\end{tabular}




\begin{tabular}{|c|c|c|c|c|}
\hline Autor(es)/Ano & Título & Área/Tema & Instituição - UF & Utilização da CIF \\
\hline & $\begin{array}{l}\text { de funcionalidade, } \\
\text { incapacidade e saúde }\end{array}$ & & & $\begin{array}{c}\text { de DPOC, AVE e } \\
\text { Alzheimer. }\end{array}$ \\
\hline $\begin{array}{c}\text { GÓES, } \\
\text { MENEZES e } \\
\text { GIVIGI, } 2017\end{array}$ & $\begin{array}{l}\text { Protocolo de avaliação } \\
\text { neurofuncional como } \\
\text { norteador da seleção de } \\
\text { ferramentas de CAA em } \\
\text { sujeitos com paralisia } \\
\text { cerebral }\end{array}$ & Neurologia & UFSE - SE & $\begin{array}{c}\text { Utilização da CIF } \\
\text { para estruturação de } \\
\text { um protocolo de } \\
\text { avaliação } \\
\text { neurofuncional. }\end{array}$ \\
\hline $\begin{array}{c}\text { ATHAYDE, } \\
\text { MANCUZO e } \\
\text { CORREA, } 2017\end{array}$ & $\begin{array}{c}\text { Influência ambiental sobre a } \\
\text { incapacidade física: uma } \\
\text { revisão sistemática da } \\
\text { literatura }\end{array}$ & Metodologia & UFMG - MG & $\begin{array}{l}\text { Investigação da } \\
\text { influência de fatores } \\
\text { ambientais sobre a } \\
\text { incapacidade física, } \\
\text { pautado no } \\
\text { referencial teórico da } \\
\text { CIF. }\end{array}$ \\
\hline $\begin{array}{l}\text { OSTROSCHI, } \\
\text { ZANOLLI e } \\
\text { CHUN, } 2017\end{array}$ & $\begin{array}{c}\text { Percepção de familiares de } \\
\text { crianças e adolescentes com } \\
\text { alteração de linguagem } \\
\text { utilizando a Classificação } \\
\text { Internacional de } \\
\text { Funcionalidade, } \\
\text { Incapacidade e Saúde (CIF- } \\
\text { CJ) }\end{array}$ & $\begin{array}{c}\text { Fonoaudiolo } \\
\text { gia }\end{array}$ & UNICAMP - SP & $\begin{array}{l}\text { Utilização da CIF-CJ } \\
\text { para avaliar a } \\
\text { percepção de } \\
\text { familiares, crianças e } \\
\text { jovens com } \\
\text { alterações de } \\
\text { linguagem. }\end{array}$ \\
\hline $\begin{array}{l}\text { SANTANA e } \\
\text { YU SHON, } \\
2017\end{array}$ & $\begin{array}{l}\text { Linguagem e funcionalidade } \\
\text { de adultos pós-Acidente } \\
\text { Vascular Encefálico (AVE): } \\
\text { avaliação baseada na } \\
\text { Classificação Internacional } \\
\text { de Funcionalidade, } \\
\text { Incapacidade e Saúde (CIF) }\end{array}$ & $\begin{array}{l}\text { Neurologia e } \\
\text { Fonoaudiolo } \\
\text { gia }\end{array}$ & UNICAMP - SP & $\begin{array}{c}\text { Utilização da CIF } \\
\text { para avaliar } \\
\text { linguagem e } \\
\text { funcionalidade em } \\
\text { pacientes com AVE. }\end{array}$ \\
\hline $\begin{array}{l}\text { FREITAS et al., } \\
\qquad 2017\end{array}$ & $\begin{array}{l}\text { Impacto da violência por } \\
\text { arma de fogo em } \\
\text { adolescentes e jovens } \\
\text { internados em hospital de } \\
\text { referência com base na } \\
\text { Classificação Internacional }\end{array}$ & Metodologia & UECE - CE & $\begin{array}{l}\text { Utilização de uma } \\
\text { lista resumida da } \\
\text { CIF para classificar a } \\
\text { funcionalidade dos } \\
\text { pacientes do estudo. }\end{array}$ \\
\hline
\end{tabular}




\begin{tabular}{|c|c|c|c|c|}
\hline$\overline{\text { Autor(es)/Ano }}$ & Título & Área/Tema & Instituição - UF & Utilização da CIF \\
\hline & $\begin{array}{l}\text { de Funcionalidade, } \\
\text { Incapacidade e Saúde }\end{array}$ & & & \\
\hline $\begin{array}{c}\text { COSTA, CORIA } \\
\text { e DUARTE., } \\
2018\end{array}$ & $\begin{array}{l}\text { Perfil funcional segundo a } \\
\text { Classificação Internacional } \\
\text { de Funcionalidade, } \\
\text { Incapacidade e Saúde em } \\
\text { pacientes queimados } \\
\text { atendidos em hospital } \\
\text { público }\end{array}$ & $\begin{array}{c}\text { Epidemiolog } \\
\text { ia }\end{array}$ & UFSE - SE & $\begin{array}{l}\text { Estabelecimento de } \\
\text { perfil funcional de } \\
\text { pacientes queimados, } \\
\text { por meio da CIF. }\end{array}$ \\
\hline $\begin{array}{l}\text { DUARTE } \text { et al., } \\
2018\end{array}$ & $\begin{array}{l}\text { Validação de um } \\
\text { instrumento de avaliação da } \\
\text { funcionalidade para } \\
\text { indivíduos com lesão } \\
\text { traumática do plexo braquial } \\
\text { - perspectiva dos pacientes }\end{array}$ & Neurologia & UFRJ - RJ & $\begin{array}{l}\text { Utilização da CIF } \\
\text { para validação de um } \\
\text { instrumento de } \\
\text { avaliação da } \\
\text { funcionalidade para } \\
\text { indivíduos com } \\
\text { LTPB. }\end{array}$ \\
\hline $\begin{array}{l}\text { ROMANO, } \\
\text { BELLEZO e } \\
\text { CHUN, } 2018\end{array}$ & $\begin{array}{l}\text { Impactos da gagueira nas } \\
\text { atividades e participação de } \\
\text { adolescentes e adultos }\end{array}$ & $\begin{array}{c}\text { Fonoaudiolo } \\
\text { gia }\end{array}$ & UNICAMP - SP & $\begin{array}{c}\text { Utilização da CIF } \\
\text { para investigar a } \\
\text { repercussão da } \\
\text { gagueira e suas } \\
\text { implicações nas } \\
\text { atividades e } \\
\text { participação de } \\
\text { adolescentes e } \\
\text { adultos. }\end{array}$ \\
\hline $\begin{array}{l}\text { BORGES, } \\
\text { MEDEIROS e } \\
\text { LEMOS } 2018\end{array}$ & $\begin{array}{c}\text { Caracterização de aspectos } \\
\text { fonoaudiológicos segundo as } \\
\text { categorias da Classificação } \\
\text { Internacional de } \\
\text { Funcionalidade, } \\
\text { Incapacidade e Saúde para } \\
\text { Crianças e Jovens (CIF-CJ) }\end{array}$ & $\begin{array}{c}\text { Fonoaudiolo } \\
\text { gia }\end{array}$ & UFMG - MG & $\begin{array}{c}\text { Classificação de } \\
\text { aspectos } \\
\text { fonoaudiológicos em } \\
\text { pacientes } \\
\text { ambulatoriais } \\
\text { utilizando a CIF-CJ. }\end{array}$ \\
\hline $\begin{array}{c}\text { PIEXAK, } \\
\text { CEZAR-VAZ e } \\
\text { BONOW, } 2019\end{array}$ & $\begin{array}{l}\text { Classificação Internacional } \\
\text { de Funcionalidade, }\end{array}$ & Conceitual & FURG - RS & $\begin{array}{l}\text { Análise de conteúdo } \\
\text { para descrição e } \\
\text { interpretação da CIF. }\end{array}$ \\
\hline Hél & - Revis & & & 6 \\
\hline
\end{tabular}




\begin{tabular}{|c|c|c|c|c|}
\hline Autor(es)/Ano & Título & Área/Tema & Instituição - UF & Utilização da CIF \\
\hline & $\begin{array}{c}\text { Incapacidade e Saúde: uma } \\
\text { Análise de Conteúdo }\end{array}$ & & & \\
\hline
\end{tabular}

Fonte: Elaborado pelos autores.

Analisando a distribuição por área temática, pode-se observar predominância das publicações na área da neurologia, seguidos de metodologia e artigos conceituais, ortopedia, fonoaudiologia, pediatria, medicina do trabalho e cardiologia, entre outros temas não menos importantes como infectologia, endocrinologia, saúde da mulher, deficiência auditiva, meio ambiente e terapia intensiva, que foram agrupados como "outros" pois apresentaram número mínimo de publicações, conforme evidenciado no Gráfico 2.

Gráfico 2. Temáticas mais frequentes nos artigos selecionados das publicações brasileiras

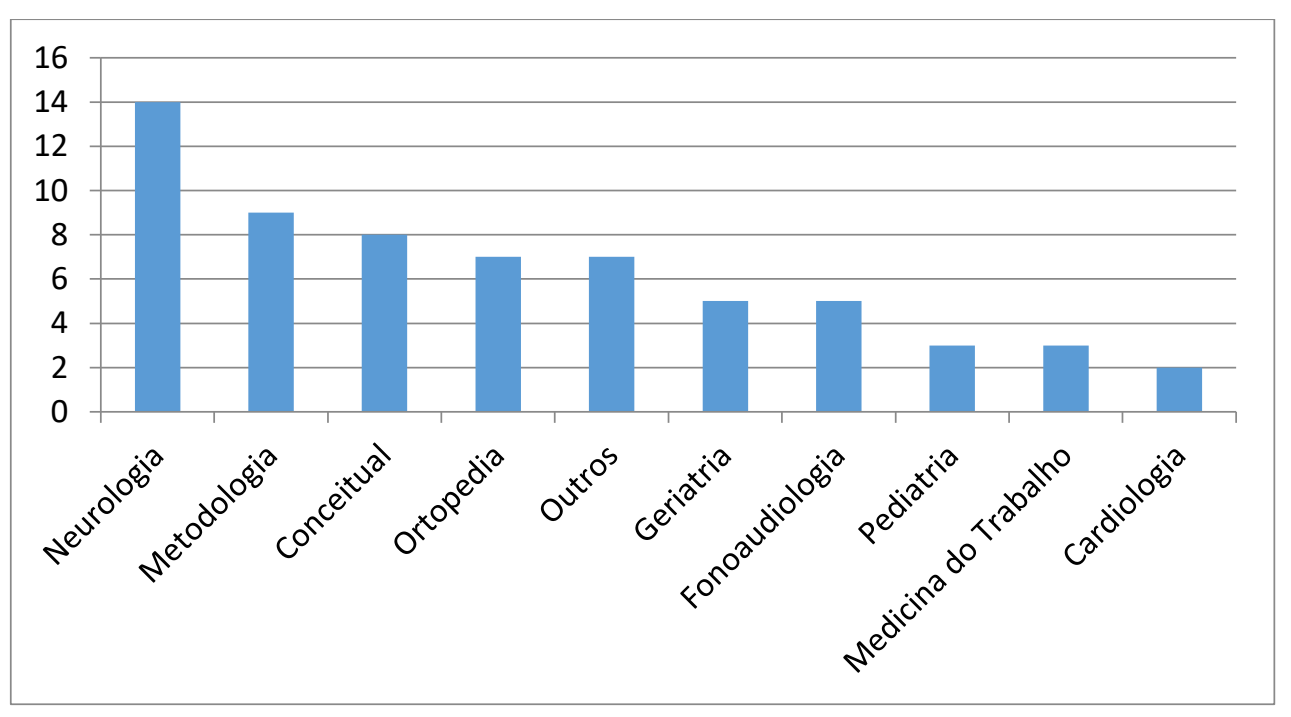

Fonte: Pesquisa bibliográfica dos autores.

Segundo Andrade (2008) o maior número de publicações na área da Neurologia se justifica por permitir o conhecimento do perfil da funcionalidade de pacientes com disfunções neurológicas, através de um método sistematizado e padronizado da CIF, entre os diferentes profissionais da saúde. Os dados descritivos de deficiências nas estruturas e funções do corpo, 
limitações nas atividades e interferência do ambiente, caracterizaram as diferentes necessidades dos casos e o modelo biopsicossocial da CIF abrange de forma completa todas as necessidades desse perfil de usuário.

Verificou-se, ainda, que 6 estudos tiveram como principal objetivo caracterizar ou avaliar o desempenho em aspectos fonoaudiológicos. Morettin et al. (2013) utilizam a CIF-CJ para caracterizar o perfil dos pacientes usuários de Implante Coclear. Já Pommerhn et al. (2016) analisaram o impacto das afasias na participação social e nas atividades dos indivíduos por elas acometidas, utilizando critérios da CIF; Ostroschi et al. (2017) utilizam a CIF-CJ para avaliar a percepção de familiares, crianças e jovens com alterações de linguagem; Santana e Chun (2017) avaliaram a linguagem e funcionalidade em pacientes com AVE utilizando a CIF; Romano et al. (2018) utilizaram a CIF para investigar a repercussão da gagueira e suas implicações nas atividades e participação de adolescentes e adultos gagos. Ainda nesse sentido, Borges et al. (2018) avaliaram aspectos fonoaudiológicos em pacientes ambulatoriais utilizando a CIF-CJ.

A CIF tem sido apontada como uma ferramenta multidimensional que permite visualizar a saúde humana sob várias vertentes, podendo ser utilizada em inúmeras áreas como Ortopedia, Cardiologia, Pediatria, Medicina do Trabalho, dentre outros temas que aparecem nessa pesquisa. Conforme demonstrado, a multidirecionalidade da CIF justifica-se por tratar-se de uma ferramenta válida e abrangente, que tem o propósito de se avaliar a funcionalidade, levando em consideração a presença e a gravidade de um problema de saúde e os impactos desses acometimentos. Com isso, a CIF e seu modelo ganham grande importância epidemiológica, já que o fator social, assim como o pessoal e a capacidade física são determinantes para o nível de saúde de uma população (FARIAS e BUCHALLA, 2005).

O modelo biopsicossocial da CIF tem seu foco voltado para funcionalidade, e com base nesse conceito a maioria das publicações encontradas na pesquisa, dezenove delas (sendo o grupo com maior representatividade), utilizavam a ferramenta para avaliar a funcionalidade. Exemplos disso foram Sabino et al. (2008) que analisaram as dificuldades de utilização da CIF para codificar atividades e participação em pacientes com problemas musculoesqueléticos nos membros inferiores e região lombar; Brasileiro e Moreira (2008) utilizaram a CIF para descrever a prevalência de alterações funcionais corpóreas em um grupo de crianças com paralisia cerebral; Depolito et al. (2009) utilizaram a CIF para relatar a evolução clinica funcional de uma idosa. 
Ainda nessa abordagem funcional, Maeno et al. (2009) abordaram o uso da CIF como ferramenta na reabilitação profissional; Simonelli et al. (2010) utilizaram a CIF como modelo de reinserção do programa de reabilitação profissional do INSS; Faria et al. (2010) compararam e avaliaram hemiparéticos com e sem história de quedas, considerando os diferentes componentes da CIF; Nickel et al. (2011) analisaram as principais limitações no desempenho em atividades e restrições na participação de indivíduos com epilepsia, classificados de acordo com a CIF; Lucena et al. (2011) utilizaram componentes da CIF para classificar atividade e participação em indivíduos com AVE, estudo parecido o de Monteiro et al. (2013) que utilizaram a CIF como avaliação sociodemográfica de pacientes com AVE.

Ainda na abordagem funcional, para avaliar o paciente holisticamente, Araújo e Buchalla (2013) fizeram menção a CIF como instrumento para a coleta de dados sobre funcionalidade, para uso na especialidade de Fisioterapia do Trabalho. Já Santos et al. (2013) utilizaram a CIF para refletir sobre o cuidado da enfermagem a pessoas idosas, igualmente Lopes e Santos (2014) e Araújo. et al. (2015) que investigaram a funcionalidade de idosos, utilizando categorias da CIF; Fleig et al. (2017) utilizaram a CIF para analisar alterações cognitivas de idosos portadores de DPOC, AVE e Alzheimer.

Silva et al. (2016) utilizaram a CIF para codificar a funcionalidade dos pacientes com disfunções do sistema cardiovascular internados em uma UTI; Góes et al. (2017) utilizaram-na para estruturação de um protocolo de avaliação neurofuncional; Freitas et al. (2018) fizeram uso de uma lista resumida da CIF para classificar a funcionalidade dos pacientes do estudo; Costa et al. (2018) usaram da ferramenta para traçar um perfil funcional dos pacientes queimados. E por fim, Duarte et al. (2018) aplicaram a CIF para validação de um instrumento de avaliação da funcionalidade para indivíduos com lesão traumática do plexo braquial.

Percebe-se, também, que 9 dos estudos não aplicaram a CIF como única ferramenta metodológica, havendo outras formas de avaliar as variáveis pesquisadas já validadas ou consagradas, fazendo, ainda, comparações entre a CIF e outro instrumento para avaliar funcionalidade, como por exemplo foram Nickel et al. (2010) que classificaram a Medida de Desempenho Ocupacional Canadense, de acordo com os domínios da CIF em pacientes com Parkinson; Castaneda e Plácido (2010) estabeleceram uma ligação entre o Questionário Kings Health e a CIF; Cardoso et al. (2012) utilizaram a versão da Classificação Internacional de Funcionalidade, Incapacidade e Saúde para Crianças e Jovens (CIF-CJ) fazendo uma comparação entre itens contidos na Avaliação da Coordenação e Destreza Motora (Acoordem). 
Atendo-se à abordagem anterior, Silva et al. (2013) avaliaram dois questionários de qualidade de vida e compararam com os componente de participação da CIF em indivíduos com AVE; Stoffel e Nickel (2013) compararam termos da CIF com outros dois instrumentos de avaliação neurológica; Castro et al. (2014) identificam o conteúdos comuns entre o Questionário do Inquérito de Saúde de São Paulo e a CIF; Castaneda et al. (2014) compararam Construtos de incapacidade presentes na Pesquisa Nacional por Amostra de Domicílio (PNAD) com a CIF; Zaponi et al. (2015) estabeleceram uma relação entre o questionário de qualidade de vida e a CIF em pacientes com Insuficiência Cardíaca Congestiva; Oliveira et al. (2017) avaliaram o Research Diagnostic Criteria for Temporomandibular Disorders e compararam com componentes da CIF em pacientes com disfunções temporomandibular.

Questões relacionadas à influência dos fatores ambientais na funcionalidade são discutidas por Brasileiro et al. (2009) que investigaram a influência dos fatores ambientais nas atividades cotidianas de crianças com paralisia cerebral; já Ferreira et al. (2013) aplicaram os componentes da CIF para avaliar um espaço público de circulação e Athayde et al. (2017) investigaram a influência de fatores ambientais sobre a incapacidade física, pautados no referencial teórico da CIF.

A instituição de ensino mais frequente nas publicações nacionais sobre a CIF foi a Universidade de São Paulo (USP-SP), com total de 8 publicações, seguido da Universidade Federal de Minas Gerais (UFMG-MG) e a Universidade Federal do Paraná (UFPR-PR) com 5 publicações de cada uma. Vale ressaltar a supremacia nacional e até internacional, $8^{\circ}$ lugar em ranking mundial, da USP, nas diversas áreas, quando o assunto é produção científica, segundo ILHÉU (2019), no Guia do Estudante da Editora Abril. O ranking foi elaborado pelo Centro de Estudos em Ciência e Tecnologia (CWTS, na sigla em inglês) da Universidade de Leiden, na Holanda.

Ao se organizar por regiões brasileiras, conforme apresentado no Gráfico 3, observouse grande predominância da região Sudeste, com mais de 50\% das publicações (27 artigos), fato que pode ser explicado em função do maior número de instituições de ensino e de pesquisa. Bezerra e Neves (2010) ratificam tais achados na medida em que ressaltam que os estados de São Paulo, Rio de Janeiro e Minas Gerais responderam por 33,72\%, 25,29\% e 10,11\% de toda a produção científica, respectivamente, sendo os estados que mais publicaram, com destaque para São Paulo, que respondeu por aproximadamente 1/3 de toda a produção. 
A região Sul foi responsável por 21\% das publicações nacionais (11 artigos), o Nordeste foi responsável por 17\% (9 artigos), seguido do Distrito Federal e Norte com uma publicação cada, o equivalente a $2 \%$ do total. Nesse quesito, vale ressaltar que há artigos publicados por mais de uma instituição, os chamados Multicêntricos, que juntos são responsáveis por 7\% das publicações totais do Brasil (4 artigos).

Gráfico 3. Publicações por região.

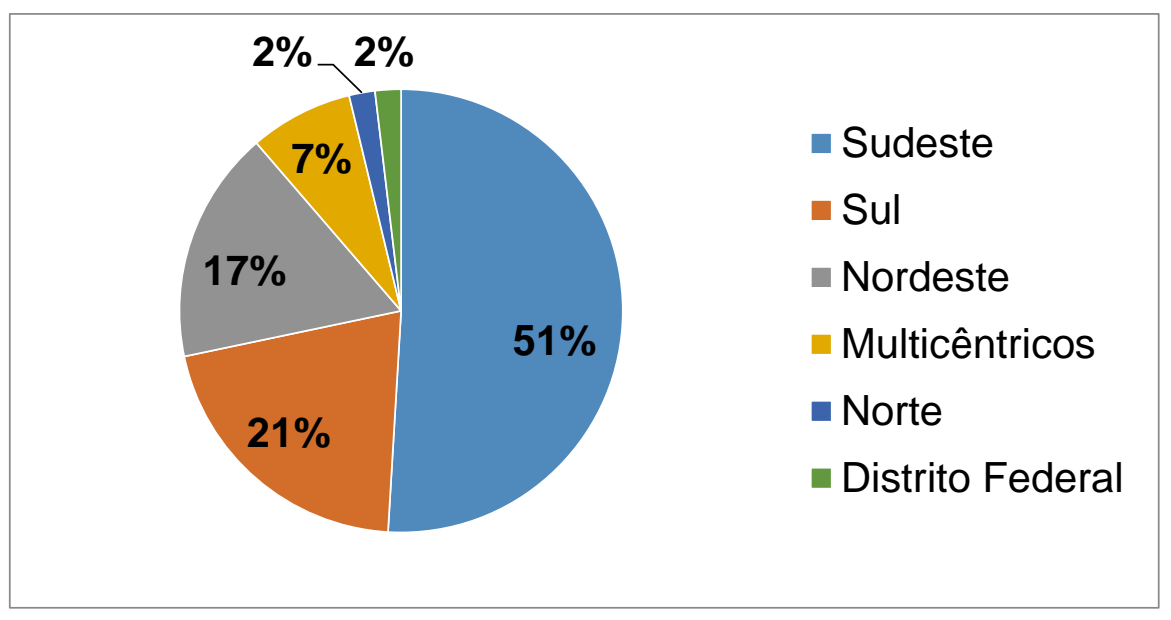

Fonte: Pesquisa bibliográfica dos autores.

A CIF foi criada visando responder às necessidades de se conhecer mais sobre as consequências das doenças, e vários estudos fazem menção a ela, ainda que não constem nos resultados dessa pesquisa, entretanto é necessário melhorar a viabilidade do seu uso. Com esse propósito Cieza et al. (2004) comentaram que o projeto core sets começou a ser desenvolvido com o objetivo de selecionar as categorias da classificação completa, que servissem como padrões mínimos para a avaliação e documentação da funcionalidade e saúde em estudos clínicos e avaliação multiprofissional abrangente. Também nesse sentido, Riberto (2011) diz que a ideia por trás dos core sets da CIF é que, ao invés de avaliar 1454 aspectos da funcionalidade das pessoas, devem-se avaliar apenas aquelas categorias que são típicas e significativas numa determinada condição de saúde.

Em 6 dos trabalhos selecionados na pesquisa, seus autores propuseram a utilização e/ou criação de core sets, como Diniz et al. (2007) que avaliaram a possibilidade de utilização do core set da CIF de dor crônica generalizada, em mulheres com fibromialgia; Buchalla e 
Cavalheiro (2008) desenvolveram o core set para pacientes portadores do vírus da AIDS; Castro et al. (2008) utilizaram o core set resumido para diabetes mellitus, a fim de avaliar a qualidade de vida de pacientes acometidos por essa patologia; Lima et al. (2008) explicaram o processo de construção do core set da CIF para LER/DORT; Riberto (2011) enumera e descreve os core sets da CIF, e Riberto et al. (2011) verificaram empiricamente a validade do core set para lombalgia.

Dos estudos analisados, 6 tiveram como objetivo principal conceituar e explicar a CIF e seus objetivos, bem como descrever seus componentes. Nesse contexto foram identificados, Farias e Buchalla (2005); Di Nubila e Buchalla (2008); Castaneda e Castro (2013); Castaneda et al. (2014); Araújo e Buchalla (2015) e Piexak et al. (2019). Tal fato justifica-se pela complexidade da ferramenta.

Outros 2 estudos fizeram menção à tradução oficial para língua portuguesa da CIF pela OMS (2003). Diniz et al. (2007) analisam e sugerem uma nova tradução, substituindo "Classificação Internacional de Funcionalidade, Incapacidade e Saúde" por "Classificação Internacional de Funcionalidade, Deficiência e Saúde”. Já Ovandro et al. (2016) avaliam a qualidade metodológica dos processos de tradução e adaptação de instrumentos de avaliação em Neurologia com base na CIF.

No campo educacional Silva et al. (2008) fizeram um rastreamento dos componentes da CIF registrados nos prontuários por acadêmicos de fisioterapia. Já no conceito de políticas públicas, Castro et al. (2016) investigaram a possibilidade da aplicação da CIF em inquéritos de saúde.

\section{CONCLUSÃO}

A CIF aparece no cenário mundial como uma ferramenta promissora e com grande potencial de adesão e aplicabilidade. Percebe-se crescente procura e aplicação dessa ferramenta na comunidade científica e acadêmica brasileira entre os anos de 2003 e 2019.

No que se refere às áreas de utilização, verificou-se predominância de estudos nas áreas relacionadas à neurologia e na avaliação da funcionalidade. Em relação à distribuição espacial, identificou-se que a maioria dos estudos foram realizados na região Sudeste. 
A aplicação do uso da ferramenta aponta para a necessidade de capacitação dos profissionais de saúde para que considerem e compreendam todas as vantagens da utilização da CIF.

Por fim, com o propósito de melhorar e ampliar o uso dessa importante ferramenta, sugere-se a adoção de medidas simples, como aumentar a divulgação e incentivar a implementação do uso da codificação da CIF nos sistemas públicos e privados de saúde.

Espera-se que profissionais e acadêmicos, munidos dessa formação, possam ter uma visão holística do indivíduo, que, mais importante que codificar e decodificar, permita a compreensão de modelos atuais de reabilitação a serem utilizados.

\section{REFERÊNCIAS}

ANDRADE, P. M. O. Avaliação da funcionalidade em crianças e adolescentes com PC e AVC: um estudo exploratório. Dissertação (Mestrado em Ciências da Saúde) - Faculdade de medicina, Universidade Federal de Minas Gerais - UFMG. Minas Gerais, p. 150. 2008. Disponível em: http://www.bibliotecadigital.ufmg.br/dspace/bitstream/handle/1843/ECJS7JYP8B/peterson_marco_de_oliveira_andrade.pdf?sequence=1. Acesso em: 31 ago. 2019.

ARAÚJO, E. S.; BUCHALLA, C. M. O uso da Classificação Internacional de Funcionalidade, Incapacidade e Saúde em inquéritos de saúde: uma reflexão sobre limites e possibilidades. Rev. bras. epidemiol., São Paulo, v. 18, n. 3, p. 720724, set. 2015. Disponível em http://www.scielo.br/scielo.php?script=sci_arttext\&pid=S1415790X2015000300720\&lng=pt\&nrm=iso. Acesso em: 30 ago. 2019.

ARAÚJO, E. S. CIF: Uma Discussão sobre Linearidade no Modelo Biopsicossocial. Rev Fisioter S Fun, Fortaleza, v. 2, n. 1, jun. 2013. Disponível em: http://www.fisioterapiaesaudefuncional.ufc.br/index.php/fisioterapia/article/view/313/pdf. Acesso em: 20 ago. 2019.

ARAÚJO, E. S.; BUCHALLA C. M. Utilização da CIF em fisioterapia do trabalho: uma contribuição para coleta de dados sobre funcionalidade. Acta Fisiátr. 2013;20(1):1-7. Disponível em: http://www.actafisiatrica.org.br/detalhe_artigo.asp?id=487. Acesso em: 30 ago. 2019.

ARAÚJO, L.B.; MOREIRA, N.B., VILLEGAS, I. L. P., LOUREIRO, A. P. C.; ISRAEL, V. L.; GATO, S. A. et al. Investigação dos saberes quanto à capacidade funcional e qualidade de vida em idosas institucionalizadas, sob a ótica da CIF. Acta Fisiátr. 2015;22(3):111-117 Disponível em: http://www.actafisiatrica.org.br/detalhe_artigo.asp?id=598\#. Acesso: em 30 ago. 2019. 
ATHAYDE, F.; MANCUZO, E. V.; CORREA, R. A. Influência ambiental sobre a incapacidade física: uma revisão sistemática da literatura. Ciênc. saúde coletiva, Rio de Janeiro, v. 22, n. 11, p. 3645-3652, nov. 2017 . Disponível em: http://www.scielo.br/scielo.php?script=sci_arttext\&pid=S141381232017021103645\&lng=pt\&nrm=iso. Acesso em: 30 ago. 2019.

BATTISTELLA, L. R.; BRITO, C. M. M. Classificação Internacional de Funcionalidade (CIF).Acta Fisiátrica, São Paulo, v. 9, n. 2, p. 98-101, aug. 2002. ISSN 2317-0190. Disponível em: https://www.revistas.usp.br/actafisiatrica/article/view/102369. Acesso em: 05 jun. 2019.

BEZERRA, M. L. S.; NEVES, E. B. Perfil da produção científica em saúde do trabalhador. Saúde soc. São Paulo, v. 19, n. 2, p. 384-394, junho de 2010. Disponível em: http://www.scielo.br/scielo.php?script=sci_arttext\&pid=S010412902010000200014\&lng=en\&nrm=iso. Acesso em: 05 de set. de 2019.

BORGES, M. G. S.; MEDEIROS, A. M.; LEMOS, S. M. A. Caracterização de aspectos fonoaudiológicos segundo as categorias da Classificação Internacional de Funcionalidade, Incapacidade e Saúde para Crianças e Jovens (CIF-CJ). CoDAS, São Paulo, v. 30, n. 4, e20170184, 2018. Disponível em http://www.scielo.br/scielo.php?script=sci_arttext\&pid=S231717822018000400311\&lng=pt\&nrm=iso. Acesso em: 30 ago. 2019.

BRASILEIRO, I.C.; MOREIRA, T.M.M.; JORGE, M.S.B. Interveniência dos fatores ambientais na vida de crianças com paralisia cerebral. Acta Fisiátr. 2009;16(3):132-137. Disponível em: http://www.actafisiatrica.org.br/detalhe_artigo.asp?id=103. Acesso em: 30 ago. 2019.

BRASILEIRO, I.C.; MOREIRA, T.M.M. Prevalência de alterações funcionais corpóreas em crianças com paralisia cerebral, Fortaleza, Ceará, 2006. Acta Fisiátr. 2008;15(1):37-41. Disponível em: http://www.actafisiatrica.org.br/detalhe_artigo.asp?id=160. Acesso em: 30 ago. 2019.

BUCHALLA, C. M.; CAVALHEIRO, T. R. A Classificação Internacional de Funcionalidade, Incapacidade e Saúde e a Aids: uma proposta de core set. Acta Fisiátr. 2008;15(1):42-48. Disponível em: http://www.actafisiatrica.org.br/detalhe_artigo.asp?id=161 . Acesso em: 30 ago. 2019.

CARDOSO, A. A. et al . Relação entre a Avaliação da Coordenação e Destreza Motora (Acoordem) e a Classificação Internacional de Funcionalidade, Incapacidade e Saúde (CIF). Fisioter. mov., Curitiba , v. 25, n. 1, p. 31-45, Mar. 2012 . Disponível em: http://www.scielo.br/scielo.php?script=sci_arttext\&pid=S010351502012000100004\&lng=en\&nrm=iso. Acesso em: 30 ago. 2019.

CASTANEDA, L.; BERGMANN, A.; BAHIA, L. A Classificação Internacional de Funcionalidade, Incapacidade e Saúde: uma revisão sistemática de estudos observacionais. Rev. bras. epidemiol., São Paulo, v. 17, n. 2, p. 437- 
451, jun. 2014. Disponível em:

http://www.scielo.br/scielo.php?script=sci_arttext\&pid=S1415-

790X2014000200437\&lng=pt\&nrm=iso. Acesso em: 30 ago. 2019.

CASTANEDA, L.; CASTRO, S. S.; BAHIA, L. Construtos de incapacidade presentes na Pesquisa Nacional por Amostra de Domicílio (PNAD): uma análise baseada na Classificação Internacional de Funcionalidade, Incapacidade e Saúde (CIF). Rev. bras. estud. popul., São Paulo, v. 31, n. 2, p. 419-429, Dec. 2014 . Disponível em: http://www.scielo.br/scielo.php?script=sci_arttext\&pid=S010230982014000200009\&lng=en\&nrm=iso. Acesso em: 30 ago. 2019.

CASTANEDA, L.; PLÁCIDO, T. Ligação do King's Heath Questionário com a Classificação Internacional de Funcionalidade, Incapacidade e Saúde, para avaliação de pacientes com incontinência urinária pós-cirurgia oncológica ginecológica. Acta Fisiátr. 2010;17(1):18-21. Disponível em: http://www.actafisiatrica.org.br/detalhe_artigo.asp?id=71. Acesso em: 30 ago. 2019.

CASTANEDA, L.; CASTRO, S. S. Publicações brasileiras referentes à Classificação Internacional de Funcionalidade. Acta Fisiátr. 2013;20(1):29-36. Disponível em: http://www.actafisiatrica.org.br/detalhe_artigo.asp?id=492. Acesso em: 30 ago. 2019.

CASTRO, S. S. et al . Aferição de funcionalidade em inquéritos de saúde no Brasil: discussão sobre instrumentos baseados na Classificação Internacional de Funcionalidade, Incapacidade e Saúde (CIF). Rev. bras. epidemiol., São Paulo, v. 19, n. 3, p. 679-687, set. 2016. Disponível em: http://www.scielo.br/scielo.php?script=sci_arttext\&pid=S1415790X2016000300679\&lng=pt\&nrm=iso. Acesso em: 30 ago. 2019.

CASTRO, C. L. N.; BRAULIO, V. B.; DANTAS, F. A. L.; COUTO, A. P. C. B. Qualidade de vida em diabetes mellitus e Classificação Internacional de Funcionalidade, Incapacidade e Saúde - estudo de alguns aspectos. Acta Fisiátr. 2008;15(1):13-17. Disponível em: http://www.actafisiatrica.org.br/detalhe_artigo.asp?id=155. Acesso em: 30 ago. 2019.

CASTRO, S. S.; CASTANEDA, L.; SILVEIRA, H.. Identificação de conteúdo comum entre o questionário do Inquérito de Saúde (ISA-SP) e a Classificação Internacional de Funcionalidade, Incapacidade e Saúde. Rev. bras. epidemiol., São Paulo , v. 17, n. 1, p. 5970, mar. 2014. Disponível em: http://www.scielo.br/scielo.php?script=sci_arttext\&pid=S1415790X2014000100059\&lng=pt\&nrm=iso. Acesso em: 30 ago. 2019.

Centro Colaborador da OMS para a Família de Classificações Internacionais em Português. CIF-CJ: Classificação Internacional de Funcionalidade, Incapacidade e Saúde: Versão para Crianças e Jovens. São Paulo: Editora da Universidade de São Paulo, 2011.

CIEZA, A.; EWERT, T. G.; USTÜN, T. B.; CHATTERJI, S.; KOSTANJSEK, N. F. e STUCKI, G. (2004). Desenvolvimento de conjuntos básicos da CIF para pacientes com doenças crônicas. Jornal de medicina de reabilitação, 44 Supl. , 9-11. Disponível em: 
https://www.medicaljournals.se/jrm/content/abstract/10.1080/16501960410015353. Acesso em: 04 de set. 2019.

COSTA, A. C. S. M.; CORIA, G. E. M.; DUARTE, L. A. M. Perfil funcional segundo a Classificação Internacional de Funcionalidade, Incapacidade e Saúde em pacientes queimados atendidos em hospital público. Rev Bras Queimaduras2018;17(1):2-7. Disponível em: http://www.rbqueimaduras.com.br/details/410/pt-BR/perfil-funcional-segundo-aclassificacao-internacional-de-funcionalidade--incapacidade-e-saude-em-pacientesqueimados-atendidos-em-hospital-publico. Acesso em: 30 ago. 2019.

DEPOLITO, C.; LEOCADIO, P. L. L. F.; CORDEIRO, R. C. Declínio funcional de idosa institucionalizada: aplicabilidade do modelo da Classificação Internacional de Funcionalidade, Incapacidade e Saúde. Fisioter. Pesqui., São Paulo, v. 16, n. 2, p. 183189, jun. 2009. Disponível em:

http://www.scielo.br/scielo.php?script=sci_arttext\&pid=S1809-

29502009000200016\&lng=pt\&nrm=iso. Acesso em: 30 ago. 2019.

DI NUBILA, H. B. V.; BUCHALLA, C. M. O papel das Classificações da OMS - CID e CIF nas definições de deficiência e incapacidade. Rev. bras. epidemiol., São Paulo, v. 11, n. 2, p. 324-335, June 2008. Disponível em: http://www.scielo.br/scielo.php?script=sci_arttext\&pid=S1415790X2008000200014\&lng=en\&nrm=iso. Acesso em: 30 ago. 2019.

DINIZ, D.; MEDEIROS, M.; SQUINCA, F.. Reflexões sobre a versão em Português da Classificação Internacional de Funcionalidade, Incapacidade e Saúde. Cad. Saúde Pública, Rio de Janeiro, v. 23, n. 10, p. 2507-2510, Oct. 2007 . Disponível em: http://www.scielo.br/scielo.php?script=sci_arttext\&pid=S0102311X2007001000025\&lng=en\&nrm=iso. Acesso em: 30 ago. 2019.

DUARTE, J.; MARTINS, J.; ANDRADE, F.; CASTANEDA, L. (2018). Validação de um instrumento de avaliação da funcionalidade para indivíduos com lesão traumática do plexo braquial - perspectiva dos pacientes. Rev Bras Neurol. 54(2):14-20, 2018. Disponível em: https://revistas.ufrj.br/index.php/rbn/article/view/19109. Acesso em: 30 ago. 2019.

ILHÉU. Taís. USP aparece em 8 lugar em ranking mundial de produção cientifica. E-Guia do Estudante, 2019. Disponível em: https://guiadoestudante.abril.com.br/estudo/usp-apareceem-8o-lugar-em-ranking-mundial-de-producao-cientifica/. Acesso em: 21 jul. 2020.

FARIAS, N.; BUCHALLA, C.M. A classificação internacional de funcionalidade, incapacidade e saúde da organização mundial da saúde: conceitos, usos e perspectivas. Rev. bras. epidemiol., São Paulo, v. 8, n. 2, p. 187-193, June 2005 . Disponível em: http://www.scielo.br/scielo.php?script=sci_arttext\&pid=S1415790X2005000200011\&lng=en\&nrm=iso. Acesso em 06 ago. 2019.

FARIA, C. D. C. M.; SALIBA, V. A.; SALMELA, L. F. T.; NADEAU, S. Comparação entre indivíduos hemiparéticos com e sem histórico de quedas com base nos componentes da Classificação Internacional de Funcionalidade, Incapacidade e Saúde. Fisioterapia e 
Pesquisa, São Paulo, v.17, n.3, p.242-7, jul./set. 2010. ISSN 1809-2950 Disponível em: http://www.revistas.usp.br/fpusp/article/view/12203/13980. Acesso em: 30 ago. 2019.

FERREIRA, E. F. B.; FOLHA, O. A. A. C.; TOBIAS, M. S. G. Avaliação da percepção sobre o ambiente de circulação: a acessibilidade centrada no usuário. Cad. Ter. Ocup. UFSCar, São Carlos, v. 21, n. 1, p. 25-33, 2013 ISSN 0104-4931. Disponível em: http://www.cadernosdeterapiaocupacional.ufscar.br/index.php/cadernos/article/view/727/41 1. Acesso em: 30 ago. 2019.

FLEIG, T. C. M.; OLIVEIRA, M. R.; GOULART, C. L.; SILVA, A. L. G. Alterações cognitivas em portadores de doenças crônicas e sua relação com a classificação internacional de funcionalidade, incapacidade e saúde. Fisioter Bras 2017;18(6):686-92. Disponível em: http://portalatlanticaeditora.com.br/index.php/fisioterapiabrasil/article/view/2049/pdf. Acesso em: 30 ago. 2019.

FREITAS, N. A.; SILVA, A. V. S.; BRASIL, A. C. O.; BASTOS, V. P. D.; BRASILEIRO I. C.; FERNANDES, L. C. B. C. Impacto da violência por arma de fogo em adolescentes e jovens internados em hospital de referência com base na Classificação Internacional de Funcionalidade, Incapacidade e Saúde. Acta Fisiátr. 2017;24(4):193-199 Disponível em: http://www.actafisiatrica.org.br/detalhe_artigo.asp?id=694 . Acesso em: 30 ago. 2019.

GÓES, U. M.; MENEZES, E. C.; GIVIGI, R. C. N. Protocolo de avaliação neurofuncional como norteador da seleção de ferramentas de CAA em sujeitos com paralisia cerebral. Distúrb Comun, São Paulo, 29(1): 133-143, março, 2017. Disponível em: https://revistas.pucsp.br/index.php/dic/article/view/32312/22356. Acesso em: 30 ago. 2019.

PARRA, M.R.; COUTINHO, R.X.; PESSANO, E.F.C. UM BREVE OLHAR SOBRE A CIENCIOMETRIA: Origem, Evolução, Tendências e sua Contribuição para o Ensino de Ciências. Revista Contexto \& Educação. Ano 34, n.107, Jan./Abr. 2019. Disponível em: www.revistas.unijui.edu.br > contextoeducacao > article > view. Acesso em: 27 jul. 2020.

LIMA, M.A.G.; NEVES, R.F.; TIRONI, M.O.S.; NASCIMENTO, A.M.D.N.; MAGALHÃES, F.B. Avaliação da funcionalidade dos trabalhadores com LER/DORT: a construção do Core Set da CIF para LER/DORT. Acta Fisiátr. 2008;15(4):229-235. Disponível em: http://www.actafisiatrica.org.br/detalhe_artigo.asp?id=126. Acesso em: 30 ago. 2019.

LOPES, G. L.; SANTOS, M. I. P. O. Funcionalidade de idosos cadastrados em uma unidade da Estratégia Saúde da Família segundo categorias da Classificação Internacional de Funcionalidade. Rev. bras. geriatr. gerontol., Rio de Janeiro, v. 18, n. 1, p. 7183, Mar. 2015. Disponível em: http://www.scielo.br/scielo.php?script=sci_arttext\&pid=S180998232015000100071\&lng=en\&nrm=iso. Acesso em: 30 ago. 2019.

LUCENA, E. M. F.; MORAIS, J. D.; BATISTA, H. R. L.; MENDES, L. M.; SILVA, K. S. Q. R.; NEVES, R. F. et al. A funcionalidade de usuários acometidos por AVE em conformidade 
com a acessibilidade à reabilitação. Acta Fisiátr. 2011;18(3):112-118. Disponível em: http://www.actafisiatrica.org.br/detalhe_artigo.asp?id=58. Acesso em: 30 ago. 2019.

MAENO, M.; TAKAHASHI, M.A.C.; LIMA, M.A.G. Reabilitação profissional como política de inclusão social. Acta Fisiátr. 2009;16(2):53-58. Disponível em: http://www.actafisiatrica.org.br/detalhe_artigo.asp?id=108. Acesso em: 30 ago. 2019.

MONTEIRO, K. S.; SOUZA, C. G.; FRANCO, C. I. F.; MOURA, J. V. Caracterização Funcional de Indivíduos Acometidos por Acidente Vascular Encefálico Assistidos em uma Unidade de Terapia Intensiva. Revista Brasileira de Ciências da Saúde. Volume 17 Número 3 Páginas 269-274 2013 ISSN 1415-2177. Disponível em: https://periodicos.ufpb.br/ojs/index.php/rbcs/article/view/14435/9809. Acesso em: 30 ago. 2019.

MORETTIN, M. et al . O uso da Classificação Internacional de Funcionalidade, Incapacidade e Saúde para acompanhamento de pacientes usuários de Implante Coclear. CoDAS, São Paulo, v. 25, n. 3, p. 216-223, 2013. Disponível em: http://www.scielo.br/scielo.php?script=sci_arttext\&pid=S2317$17822013000300005 \& \operatorname{lng}=$ en\&nrm=iso. Acesso em: 30 ago. 2019.

NICKEL, R.; PINTO. L. M.; LIMA. A. P.; NAVARRO, E. J.; TEIVE, H. A. G.; BECKER, N. et al. Estudo descritivo do desempenho ocupacional do sujeito com doença de Parkinson: o uso da CIF como ferramenta para classificação da atividade e participação. Acta Fisiátr. 2010;17(1):13-17. Disponível em: http://www.actafisiatrica.org.br/detalhe_artigo.asp?id=70. Acesso em: 30 ago. 2019.

NICKEL, R.; SOUZA, J. R. B.; SILVEIRA, N. L.; ROBERT, C.; LIMA, A. P.; NAVARRO, E. J. et al. Estudo descritivo sobre o desempenho ocupacional do sujeito com epilepsia: o uso da CIF como ferramenta para classificação da atividade e participação. Acta Fisiátr. 2011;18(2):55-59. Disponível em: http://www.actafisiatrica.org.br/detalhe_artigo.asp?id=78. Acesso em: 30 ago. 2019.

OLIVEIRA, F. V. A. O. et al. Proposta de utilização da Classificação Internacional de Funcionalidade, Incapacidade e Saúde na avaliação da disfunção temporomandibular. Fisioter Bras 2017;18(3):294-305. Disponível em:

http://portalatlanticaeditora.com.br/index.php/fisioterapiabrasil/article/view/1053/2112. Acesso em: 30 ago. 2019.

ORGANIZAÇÃO MUNDIAL DE SAÚDE (OMS). Classificação Internacional de Funcionalidade Incapacidade e Saúde, 2001. Disponível em: https://www.who.int/classifications/icf/en/\#. Acesso em: 11 jul. 2019.

ORGANIZAÇÃO MUNDIAL DA SAÚDE (OMS) Como usar a CIF: Um manual prático para o uso da Classificação Internacional de Funcionalidade, Incapacidade e Saúde (CIF). Versão preliminar para discussão. Genebra. Outubro de 2013. 
OSTROSCHI, D. T.; ZANOLLI, M. L.; CHUN, R. Y. S. Percepção de familiares de crianças e adolescentes com alteração de linguagem utilizando a Classificação Internacional de Funcionalidade, Incapacidade e Saúde (CIF-CJ). CoDAS, São Paulo, v. 29, n.

3, e20160096, 2017. Disponível em:

http://www.scielo.br/scielo.php?script=sci_arttext\&pid=S2317-

17822017000300309\&lng=pt\&nrm=iso. Acesso em: 30 ago. 2019.

OVANDO, A. C.; PERES, D.; MICHAELSEN, S. M.; NORONHA, M. A. Processo de tradução, propriedades de medida e classificação de acordo a CIF dos instrumentos de avaliação pós-AVE disponíveis em Português falado no Brasil. Fisioter Bras 2016;17(4):40014. Disponível em:

http://portalatlanticaeditora.com.br/index.php/fisioterapiabrasil/article/view/513/1489. Acesso em: 30 ago. 2019.

PIEXAK, D. R.; CEZAR-VAZ, M. R.; BONOW, C. A. International Classification of Functioning, Disability and Health: a Content Analysis / Classificação Internacional de Funcionalidade, Incapacidade e Saúde: uma Análise de Conteúdo. Revista de Pesquisa:

Cuidado é Fundamental Online, [S.1.], v. 11, n. 2, p. 363-369, jan. 2019. ISSN 2175-5361. Disponível em: http://www.seer.unirio.br/index.php/cuidadofundamental/article/view/6565. Acesso em: 30 ago. 2019.

POMMEREHN, J; DELBONI, M. C. C.; FEDOSSE, E. Classificação Internacional de Funcionalidade, Incapacidade e Saúde e afasia: um estudo da participação social. CoDAS, São Paulo, v. 28, n. 2, p. 132-140, abr. 2016 . Disponível em: http://www.scielo.br/scielo.php?script=sci_arttext\&pid=S2317-

$17822016000200132 \& \operatorname{lng}=$ pt\&nrm=iso. Acesso em: 30 ago. 2019.

RIBERTO, M. et al . A experiência brasileira com o core set da classificação internacional de funcionalidade, incapacidade e saúde para lombalgia. Coluna/Columna, São Paulo, v. 10, n. 2, p. 121-126, 2011. Disponível em:

http://www.scielo.br/scielo.php?script=sci_arttext\&pid=S1808-

$18512011000200008 \& \operatorname{lng}=$ pt\&nrm=iso. Acesso em: 30 ago. 2019.

RIBERTO, M. Core sets da Classificação Internacional de Funcionalidade, Incapacidade e Saúde. Rev. bras. enferm., Brasília, v. 64, n. 5, p. 938-946, out. 2011 . Disponível em: http://www.scielo.br/scielo.php?script=sci_arttext\&pid=S0034-

$71672011000500021 \& \operatorname{lng}=$ pt\&nrm=iso. Acesso em: 05 agosto 2019.

RIBERTO, M.; SARON, T. R. P.; BATTISTELLA, L. R. Resultados do core set da CIF de dor crônica generalizada em mulheres com fibromialgia no Brasil. Acta Fisiátr.

2008;15(1):6-12. Disponível em: http://www.actafisiatrica.org.br/detalhe_artigo.asp?id=156. Acesso em: 30 ago. 2019.

ROMANO, N.; BELLEZO, J. F.; CHUN, R. Y. S. Impactos da gagueira nas atividades e participação de adolescentes e adultos. Distúrb Comun, São Paulo, 30(3): 510-521, setembro, 2018.Disponível em: http://revistas.pucsp.br/dic/article/view/35790/26633. Acesso em: 30 ago. 2019. 
SABINO, G. S.; COELHO, C. M.; SAMPAIO, R. F. Utilização da Classificação Internacional de Funcionalidade, Incapacidade e Saúde na avaliação fisioterapêutica de indivíduos com problemas musculoesqueléticos nos membros inferiores e região lombar. Acta Fisiátr. 2008;15(1):24-30. Disponível em:

http://www.actafisiatrica.org.br/detalhe_artigo.asp?id=158. Acesso em: 30 ago. 2019.

SANTOS, S. S. C. et al . Classificação internacional de funcionalidade, incapacidade e saúde: utilização no cuidado de enfermagem a pessoas idosas. Rev. bras. enferm., Brasília, v. 66, n. 5, p. 789-793, Oct. 2013 . Disponível em:

http://www.scielo.br/scielo.php?script=sci_arttext\&pid=S0034-

$71672013000500021 \& \operatorname{lng}=e n \& n r m=$ iso. Acesso em: 30 ago. 2019.

SANTANA, M. T. M.; YU SHON, R. Linguagem e funcionalidade de adultos pós-AVC: avaliação baseada na Classificação Internacional de Funcionalidade, Incapacidade e Saúde (CIF). CoDAS , São Paulo, v. 29, n. 1, e20150284, 2017. Disponível em:

http://www.scielo.br/scielo.php?script=sci_arttext\&pid=S2317-

17822017000100306\&lng=en\&nrm=iso. Acesso em: 30 ago. 2019.

SILVA, A. C. L.; NEVES, R. F.; RIBERTO, M. A formação fisioterapêutica no campo da ortopedia: uma visão crítica sob a óptica da funcionalidade. Acta Fisiátr. 2008;15(1):18-23. Disponível em: http://www.actafisiatrica.org.br/detalhe_artigo.asp?id=157. Acesso em: 30 ago. 2019.

SILVA, B. N. O.; SOUZA, R. C.; CARVALHO, T. P. V.; NETO, M. L. P.; MACIEL, L. Y. S. et al. Aplicação da classificação internacional de funcionalidade, incapacidade e saúde em Unidade de Terapia Intensiva Cardiotorácica. Fisioter Bras 2016;17(2):107-18. Disponível em:

http://www.portalatlanticaeditora.com.br/index.php/fisioterapiabrasil/article/view/196/1414. Acesso em: 30 ago. 2019.

SILVA, S. M. et al . Comparação entre instrumentos de qualidade de vida para avaliação da participação apos AVE conforme a Classificação Internacional de Funcionalidade, Incapacidade e Saúde (CIF). Braz. J. Phys. Ther., São Carlos , v. 17, n. 5, p. 470478, out. 2013 . Disponível em http://www.scielo.br/scielo.php?script=sci_arttext\&pid=S1413$35552013000500470 \& \operatorname{lng}=$ pt\&nrm=iso. Acesso em 30 ago. 2019.

SIMONELLI, A. P. et al . Proposta de articulação entre abordagens metodológicas para melhoria do processo de reabilitação profissional. Rev. bras. saúde ocup., São Paulo, v. 35, n. 121, p. 64-73, Jun 2010 . Disponível em:

http://www.scielo.br/scielo.php?script=sci_arttext\&pid=S0303-

$76572010000100008 \& \operatorname{lng}=e n \& n r m=$ iso. Acesso em: 30 ago. 2019.

SOUZA, Marcela Tavares de; SILVA, Michelly Dias da; CARVALHO, Rachel de. Revisão integrativa: o que é e como fazer. Einstein (São Paulo), São Paulo, v. 8, n. 1, p. 102- 
106, Mar. 2010 . Disponível em: http://www.scielo.br/scielo.php?script=sci_arttext\&pid $=$ S1679-45082010000100102\&lng=en\&nrm=iso. Acesso em: 28 Jul. 2020.

STOFFEL, D. P.; NICKEL, R. A utilização da atividade como ferramenta no processo de intervenção do terapeuta ocupacional em reabilitação neurológica. ISSN 0104-4931 Cad. Ter. Ocup. UFSCar, São Carlos, v. 21, n. 3, p. 617-622, 2013. Disponível em: http://doi.editoracubo.com.br/10.4322/cto.2013.064. Acesso em 30 ago. 2019.

ZAPONI, R. S.; FREZ, A. R.; MORA, C. T. R.; RUARO, J. A.; DANIEL, C. R. Avaliação da qualidade de vida de portadores de insuficiência cardíaca congestiva e sua correlação com a Classificação Internacional de Funcionalidade, Incapacidade e Saúde. Acta Fisiátr. 2015;22(3):105-110. Disponível em:

http://www.actafisiatrica.org.br/detalhe_artigo.asp?id=588. Acesso em: 30 ago. 2019.

\section{Declaração de Interesse}

Os autores declaram não haver nenhum

conflito de interesse.

\section{Financiamento}

Financiamento próprio

\section{Colaboração entre autores}

L. M. S. idealizou, efetivou a pesquisa e escreveu o artigo que constituiu o Trabalho de Conclusão de Curso de Fisioterapia em 2019. F. C. S. orientou e acompanhou o delineamento e execução da pesquisa, bem como efetuou a revisão do texto. 